\title{
Skeletal Anomalies
}

\author{
Machado LE ${ }^{1}$, Bonilla-Musoles $\mathrm{F}^{2}$, Obsborne $\mathrm{N}^{3}$, Sanz $\mathrm{M}^{2}$, Raga $\mathrm{F}^{2}$, \\ Machado $\mathrm{F}^{1}$, Bonilla Jr $\mathrm{F}^{1}$, Dolz $\mathrm{M}^{2}$ \\ ${ }^{1}$ INTRO, Salvador (Ba), Brazil \\ ${ }^{2}$ Department of Obstetrics and Gynecology, Valencia School of Medicine, Spain \\ ${ }^{3}$ Howard University, Washington
}

\section{INTRODUCTION}

The development of the thorax, the central nervous system (CNS) as well as the peripheral nervous system during the intrauterine life is of most importance for the posterior wellbeing of life, especially because many of their abnormalities are compatible with life and can create serious disabilities.

Therefore, the prenatal diagnosis of these defects, especially the open ones, is essential for the correct neonatal treatment, especially, when the effort is being made to give an intrauterine surgical solution to some of these abnormalities (myelomeningocele).

The neurological postnatal prognosis will depend, therefore, on the intrauterine diagnosis as early as possible, of:

- The vertebral level where the medullar injury is located (Iniencephaly)

- If it is a simple deviation, or if the medulla is exposed or not to the contact of amniotic fluid (spina bifida, myelomeningocele)

- If is truly a partial or broad defect

- Existence of a tumor (teratomas, etc.), or

- If there is a complete or incomplete function of two spines (Siamese twins).

In the last decades study of vertebral and medullary canal has not been simple, and the level of false-negative diagnosis, in spite of indirect ultrasound signs that usually come along with them, are one of the most found malformations (Fig. 1).

The ultrasound advances in the last decade using 3D and all its transparency modes, have open new hope that was unthinkable so far.

\section{SKELETAL ANOMALIES}

The diagnosis of skeletal malformations using 2D is not always easy.

The skeletal anomalies comprise a number of entities of low incidence (2 per 10,000 newborns). Half of these anomalies are lethal because of a narrow thorax with hypoplastic lungs.

Lethal skeletal anomalies associated with hypoplastic lungs are responsible for 0.9 percent of all perinatal deaths.
Thanatophoric dysplasia, the most common lethal osteochondrodysplasia, occurs with an estimated frequency of 0.5 and 0.69 cases in 100,00 newborns. A recent study in Spain reported an incidence of 2.53 to 2.70 cases of achondroplastic dysplasia, but the worldwide frequency is estimated at between 5.0 and 6.9 cases per 100.000 newborns. In other words, one fourth of all congenital skeletal anomalies are due to thanatophoric dysplasia.

\section{CLASSIFICATION OF SKELETAL DYSPLASIA}

Skeletal dysplasia is frequently associated with limb malformations. Although they are usually divided into five different types, a universally accepted classification is still lacking, mainly because of a lack of uniformity in the criteria used for diagnosis. The types of skeletal dysplasia that are generally recognized are as follows.

\section{Osteochondrodysplasia}

This involves alterations in the growth and development of bone and cartilage. The most frequent forms are osteogenesis

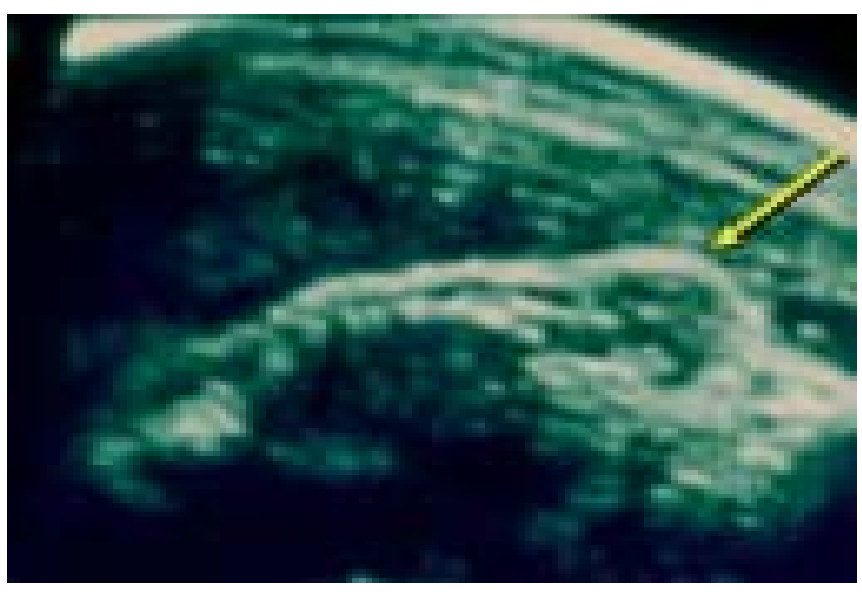

Fig. 1: Spina bifida: 70's image that shows, using the static system, an anterior open of the spinal apophysis 
imperfecta, achondroplasia, thanatophoric dysplasia, and achondrogenesis.

\section{Dysostosis}

This refers to isolated malformations of single bones or of combination of bones. A few examples of this anomaly are craniosynostosis, craniofacial dysostosis or Crouzon's disease, mandibulofacial dysostosis, achiria, apodia, polydactyly, syndactyly, Poland syndrome, and brachydactyly.

\section{Idiopathic Osteolysis}

This is a disorder associated with multifocal bone resorption.

\section{Skeletal Disorders Resulting from Chromosomal Defects}

These disorders may result from either de novo chromosomal mutations or aneuploidia. In some cases, these disorders can result from dominant or recessive Mendelian inheritance.

\section{Skeletal Abnormalities Resulting from Primary Metabolic Disorders}

Skeletal abnormalities resulting from primary metabolic disorders are conditions such as hypophosphatasia (i.e. osteogenesis imperfecta) in which severely demineralized bone secondary to congenital alkaline phosphatase deficiency leads to skeletal abnormalities that are incompatible with postnatal life. Although the disorder has an autosomal-recessive type of inheritance, the skeletal deformities result from the marked bone demineralization caused by alkaline phosphatase deficiency.

Despite the reported low incidence of thanatophoric dwarfism, we had the opportunity to examine nine cases of this malformation. In seven cases polyhydramnios was present, improving the observation of the foetuses and allowing a more accurate diagnosis.

The typical cloverleaf-shaped skull image is usually seen in 14 percent of cases.

This finding allows classification into the following two types of thanatophoric dysplasia. Fetuses with:

1. Type I: The most frequent, characterized by:

- Curved and short long bones

- Femur with the shape of a telephone receiver

- Fibulae shorter than tibiae

- Platyspondylia resulting in mild kyphosis

- Cloverleaf-shaped skull is absent.

The narrow, short ribs along with flat vertebrae bodies result in a short and narrow chest. The presence of a mid-face hypoplasia, depressed nasal bridge, and a. full forehead gives them the appearance of having a "boxer's face”.
2. Type II: It has in addition a:

- Cloverleaf-shaped, trilobed skull, with

- Straighter femora and taller vertebral bodies than those seen in fetuses with type 1.

In both types, polyhydramnios is usually seen in the late second and third trimesters.

Without a family history of osteochondrodysplasia, or a 2D examination by an expert sonographer during the second half of pregnancy, these anomalies may by completely missed or may be erroneously diagnosed as intrauterine growthrestricted fetuses.

Because of the many types of skeletal malformations, definitive diagnosis of specific skeletal anomalies with 20 can be difficult.

\section{Ultrasound Diagnosis}

At present, there are few references to skeletal dysplasia diagnosed prenatally with 3D.

Descriptions of phocomelia, thrombocytopenia with absence of the radius, platyspondylia, anomalies of the ribs, and Takayasu's disease, have already been published.

The use of 3D transparency/X-ray mode allows visualization of the spine and thorax, evaluation of the curvature of the ribs, observation of the vertebrae, medullar canal, clavicles and scapulae, and completes the study with the visualization of the form, angulations, and length of the long bones.

In our experience, the best time to obtain good quality $2 \mathrm{D}$ and 3D images is between weeks 18th and 32nd of gestation, selecting an amniotic fluid sonic window that allows excellent 2D and 3D sagittal and frontal views of the fetus.

Ultrasound presumptive diagnosis is based on:

- Megacephaly (Fig. 2) with cloverleaf-shaped skull and progressive hydrocephaly.

- Hypoplastic thorax that is disproportionately small in relation to the abdomen (bell-shaped thorax in the form of a “champagne bottle cork”)

- Ribs and bones of the extremities those are short and curved. Femurs which often show the shape of a "telephone receiver”

- Excess of skin that confers a "boxer's face” aspect

- Flattened vertebrae with diminution of the intervertebral space, giving the vertebral body the form of an " $\mathrm{H}$ " and increasing the short and narrow appearance of the thorax.

- Presence of polyhydramnios in most cases.

All these characteristics can be observed, with greater or lesser frequency, using 2D (Table 1).

A macrocephalic fetus, which shows a cloverleaf-shaped skull with Boxer's face, a typically short and hypoplastic thorax with "champagne-bottle" shape, a very prominent abdomen 


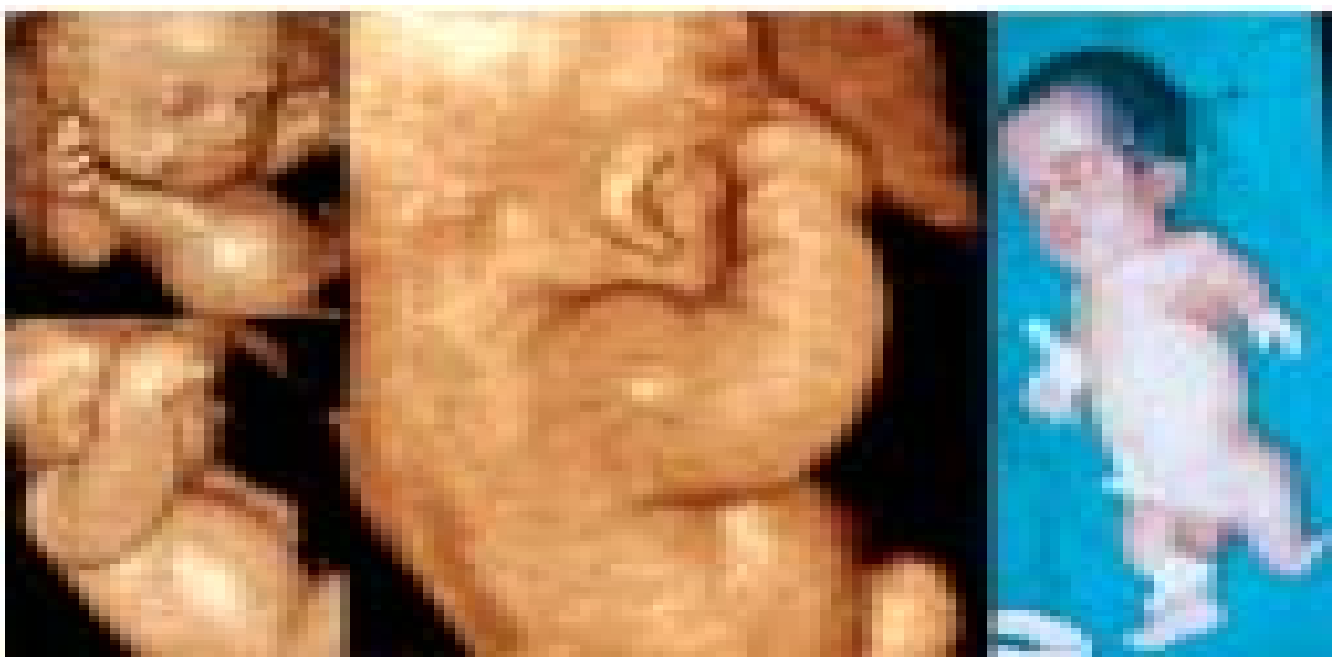

Fig. 2: Thanatophoric dwarfism: Detail of hands, facies, nose, ears and cloverleaf head, short thorax, prominent abdomen

Table 1: The classical US findings either for 2D or 3D

\begin{tabular}{ll}
\hline Ultrasound findings & Frequencies \\
\hline Generalized micromelia & Always \\
Small-champagne-shape chest & Always \\
Short or very short thorax & Always \\
Prominent abdomen & Always \\
Macrocephaly & High \\
Cloverleaf-shape head & Middle \\
Frontal bossing & Middle \\
Brachycephaly & Low \\
Depressed nasal bridge & Always \\
Omphalocele & Very low \\
Bicuspid aortic valve & Very low \\
Atrial septal defect or single atrium & Very low \\
Short and/or thick ribs & High \\
Short femurs & Always \\
Curved extremities & Always \\
Telephone receiver-shape femurs & Low \\
Angulations and deformities of long bones & High \\
Platyspondylia & Middle \\
Trident hand & Low \\
Excessive skin folds and edema & High \\
Polyhydramnios & High \\
Boxer's faces & High \\
\hline
\end{tabular}

due to the shortened thorax, curved extremities, curved ribs, telephone-shaped femur; "boxer's face" due to excess skin, " $H$ shaped" vertebrae (platyspondylia) with decreased intervertebral thorax spaces and polyhydramnion.

\section{Comments}

Thanatophoric dysplasia is the most common of the lethal osteochondrodysplasias, and all newborns with this condition die during the first hours of life.
The first prenatal diagnosis using the polymerase chain reaction to analyze DNA from amniotic fluid cells suggests that there is a mutation in gene 3 of the growth factor of fibroblasts.

Although an autosomal-recessive transmission has been suggested, the etiology of this disorder, which has an estimated recurrence rate of 2 percent, is likely to be multifactorial.

\section{Achondroplasia}

Autosomal-dominant disorders related to a defect in the short arm of chromosome 4 that can be homozygous (always lethal) or heterozygous (mostly live newborns).

The diagnosis is made on the basis of family history (although most are de novo mutations) and by the following US markers:

- Short extremities, mainly rhizomelia. Femoral length usually in the 50th percentile at 18th week, in the 30th percentile at 20-week, and below the 5th percentile at 22nd week. The humerus is short by 22nd week, and the rest of the long bones display a moderate shortening

- Long and narrow thorax and lumbar lordosis

- Enlarged head with frontal swelling (attention should be paid to the relationship biparietal diameter/thorax diameter). Sometimes, megalencephaly is observed by disproportion between the base of the skull and the vault. For that reason, the cases can also present with hydrocephaly.

Joint hyperextension, especially of the knee, is also commonly observed.

\section{Osteogenesis Imperfecta Type II}

Autosomal-recessive disorder characterized by diffuse hypomineralization. These are distinguished by:

- Shortening, angulations, curving, or multiple fractures of long bones 


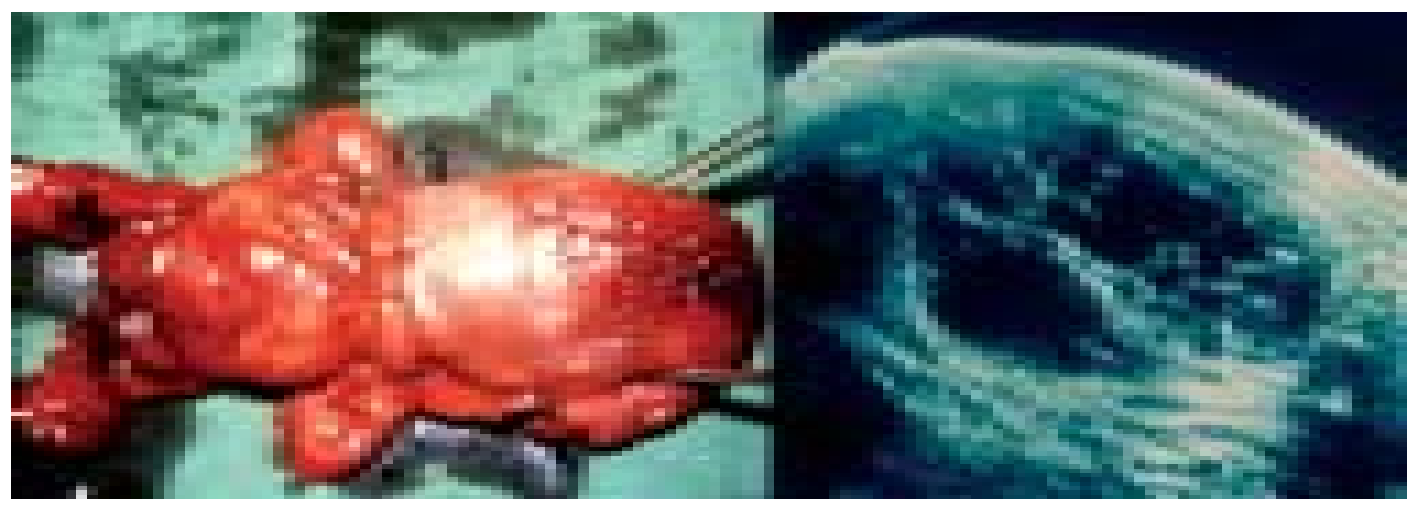

Fig. 3: Osteogenesis imperfecta, lethal type II

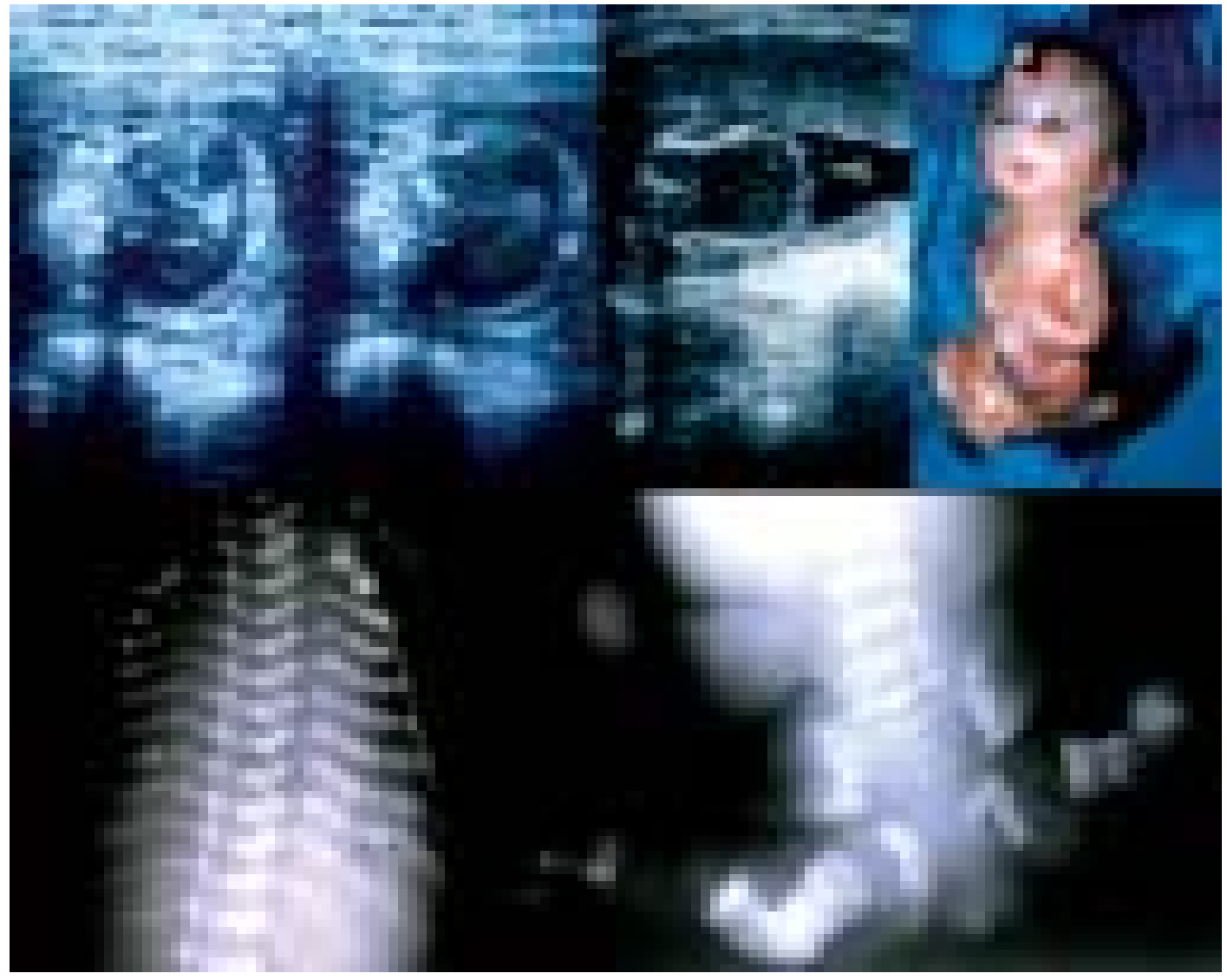

Fig. 4: Osteogenesis imperfecta, lethal type II. 2D and X-ray examination

- Increased osseous transparency without posterior sonic shadow

- Demineralized and thin skull

- Multiple fractures, costal fractures.

The combination of 2D and 3D is ideal for the diagnostic accuracy in these dysplasias. Two-dimensional US allow a better vision and measurement of the long bones and internal organs. Three-dimensional US allow a more realistic surface vision (Figs 3 and 4).

\section{MEDULLARY CANAL ANOMALIES Iniencephaly}

Iniencephaly is a very rare and complex malformation, first described by van Saint Hilaire in 1836, consisting of an apertus or clausus neural tube defect, with a skull malformation in the areas of the occiput. The occipital bone is missing or has a large hole connecting it to the foramen magnum, making it extremely wide and irregular. Through this defect the brain can arrear externally protruded. 
All the cases show neural tube defects at least affecting the cervical vertebrae, but cases have been reported in which the entire medullar canal is open. The cervical / cervicothoracic part of the spinal column exhibits extreme lordosis as a consequence of the disintegration of the affected vertebrae, which are reduced in size and number, fused to the cranium and opened. These vertebral anomalies give rise to a reduction in the crown-rump length.

The consequences of these vertebral defects are as follows:

- An extremely extended head, which may be fixed, giving the affected fetuses (and newborns) their characteristic appearance.

- The face looks upward in a so-called "star-gazing" position. Protrusion and torsion of the chest. Lung hypoplasia (occasionally)

- Polyhydramnios (40\%), due to swallowing difficulty

- Iniencephaly is both rare and heterogeneous in terms of associated intracranial and skeletal anomalies. Female fetuses are more commonly affected (Fig. 5).

The etiology of iniencephaly is still unknown, but has been associated with syphilis and intake of sedatives, tetracycline's and vinblastine.

The ultrasonic diagnosis reveals the following:

- An inability to locate the entire fetal spine on a longitudinal scan

- Visualization of an occipital and cervical mass

- An extremely extended head (star-gazing) in sagittal view.

- Visualization of the head when scanning the thorax transversely (due to the hyperextended head)

- Shortened neck, crown-rump length and spine.

The prognosis is generally fatal, although some cases of survival have been published.

Some cases have reported this as an isolated anomaly, although 84 percent are associated with other malformations of the head (anencephaly, microcephaly, hydrocephaly, holoprosencephaly, agenesis of the corpus callosum, encephalocele, cyclopia), as well as facial (cleft lip and palate) cardiovascular and genitourinary malformations, abdominal wall defects, diaphragmatic hernia, joint and limb anomalies.

\section{Neural Tube Defects}

The spine is an integrated system of bones, cartilage, joints and membranous structures that protects the fundamental part of the nervous system and at the same time gives support to the skeleton (Figs 6 to 9).

Reports of sonographic studies have been published over two decades, showing the origin of the three ossification centers as one at each lamina-pedicle junction and one in the vertebral body. In 1991 it was reported the sonographic evaluation of the neural arch ossification centers of the distal fetal spine and that this ossification occurred in a predictable pattern, in a caudal

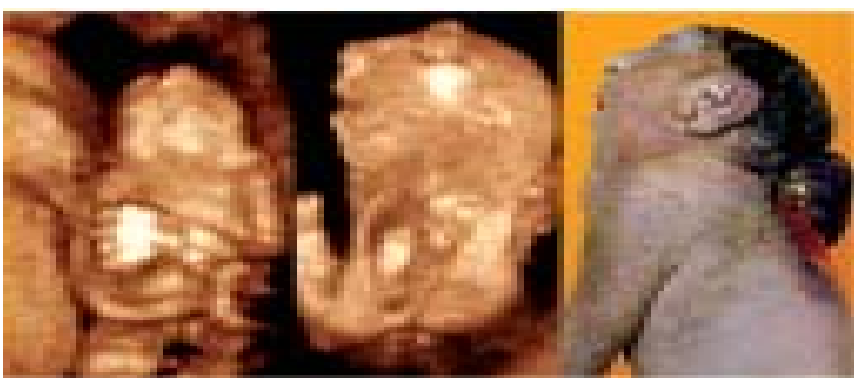

Fig. 5: Iniencephaly; hyperextended head; star-gazing face; short and fixed neck; occipital protruding tumor; open mouth; cervical apertus neural tube defect; protrusion and torsion of the thorax; restricted $\mathrm{CRL}$; exophthalmia

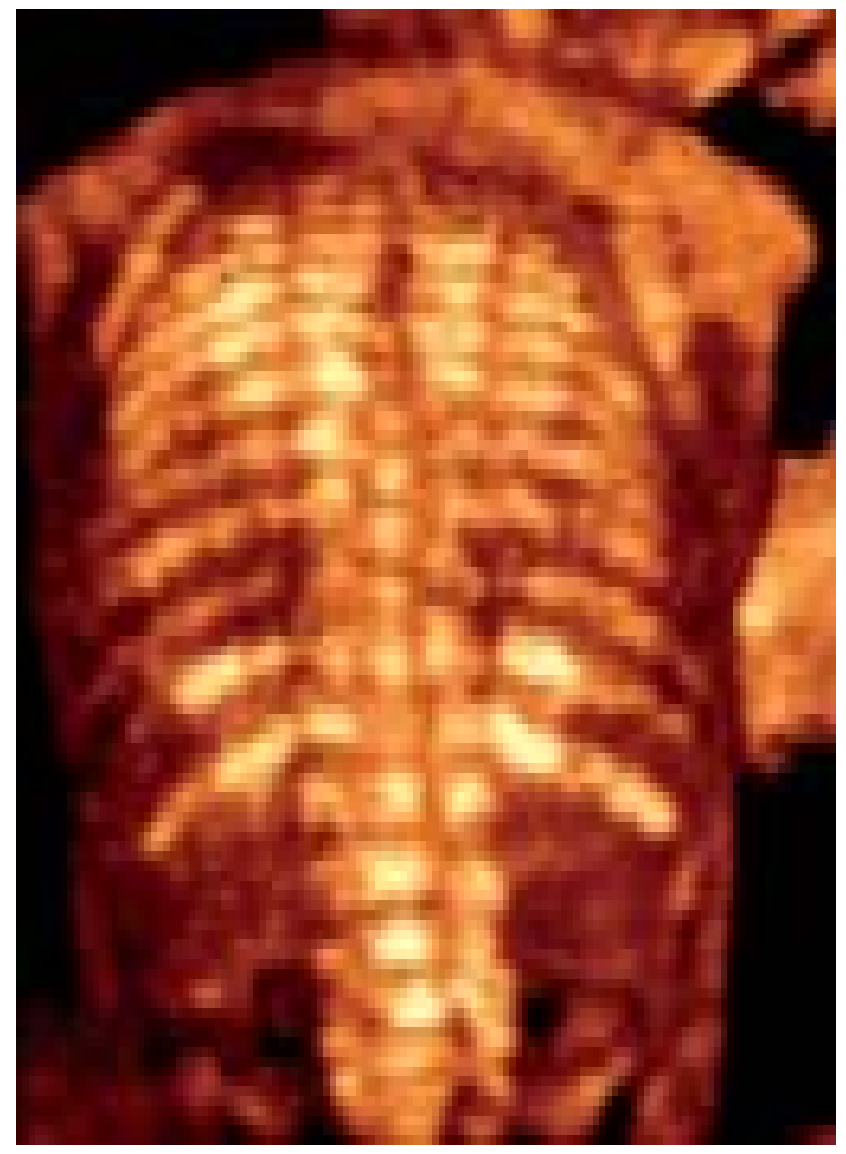

Fig. 6: Normal column. Normal development and morphology of the spine and ribs

direction and that an additional vertebral level became ossified every 2 to 3 weeks from L-5 and, S-2 was ossified by 22 weeks.

Sonographic lesion level and pathologic level were in agreement in 64 percent of cases with spina bifida and were within one spinal level in 79 percent allowing accurate prediction of spina bifida lesion level and neuromotor handicap.

Demonstration of spinal/vertebral structures by using 3D ultrasound has been reported from 1996. Riccabona demonstrated the continuity of the spine and ribs. Müeller 


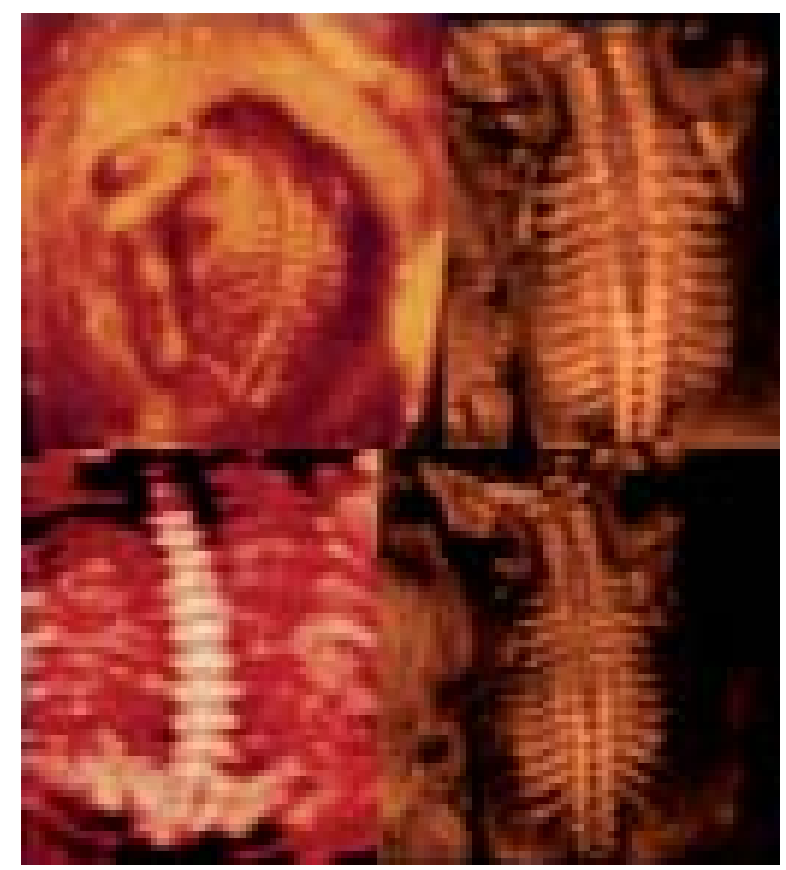

Fig. 7: Normal fetal rachis with its closing process: When using maximum transparency and X-ray, it is possible to carry out the whole visualization of the medullar canal, vertebrae and intervertebral space

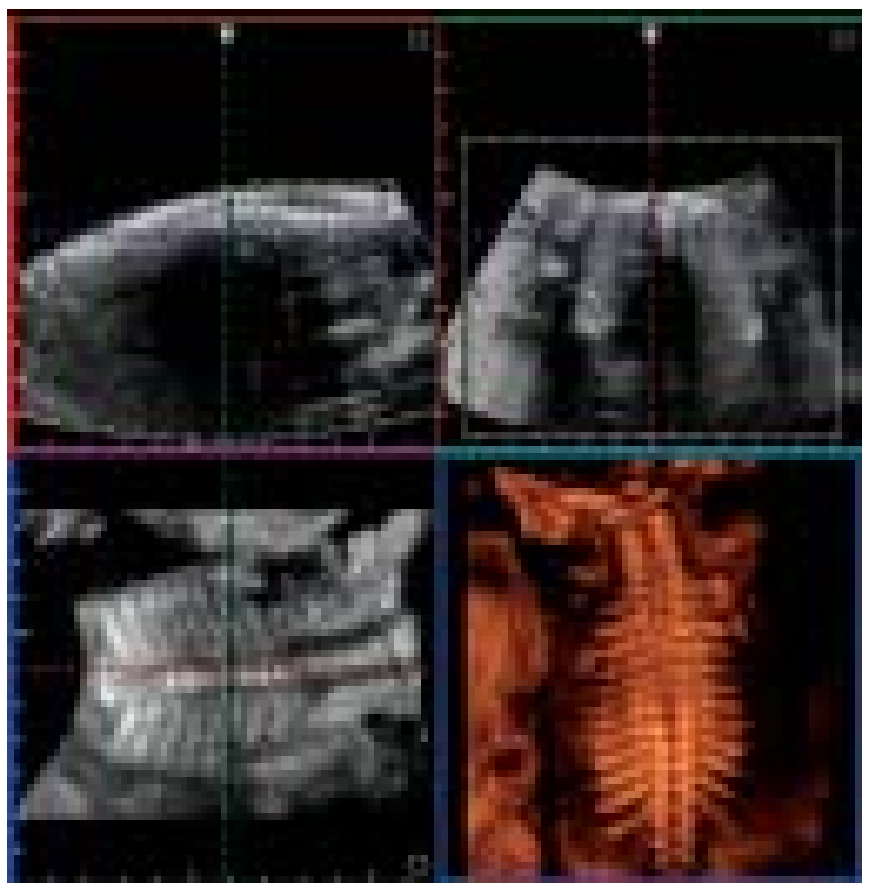

Fig. 8: 4D study of a normal spine

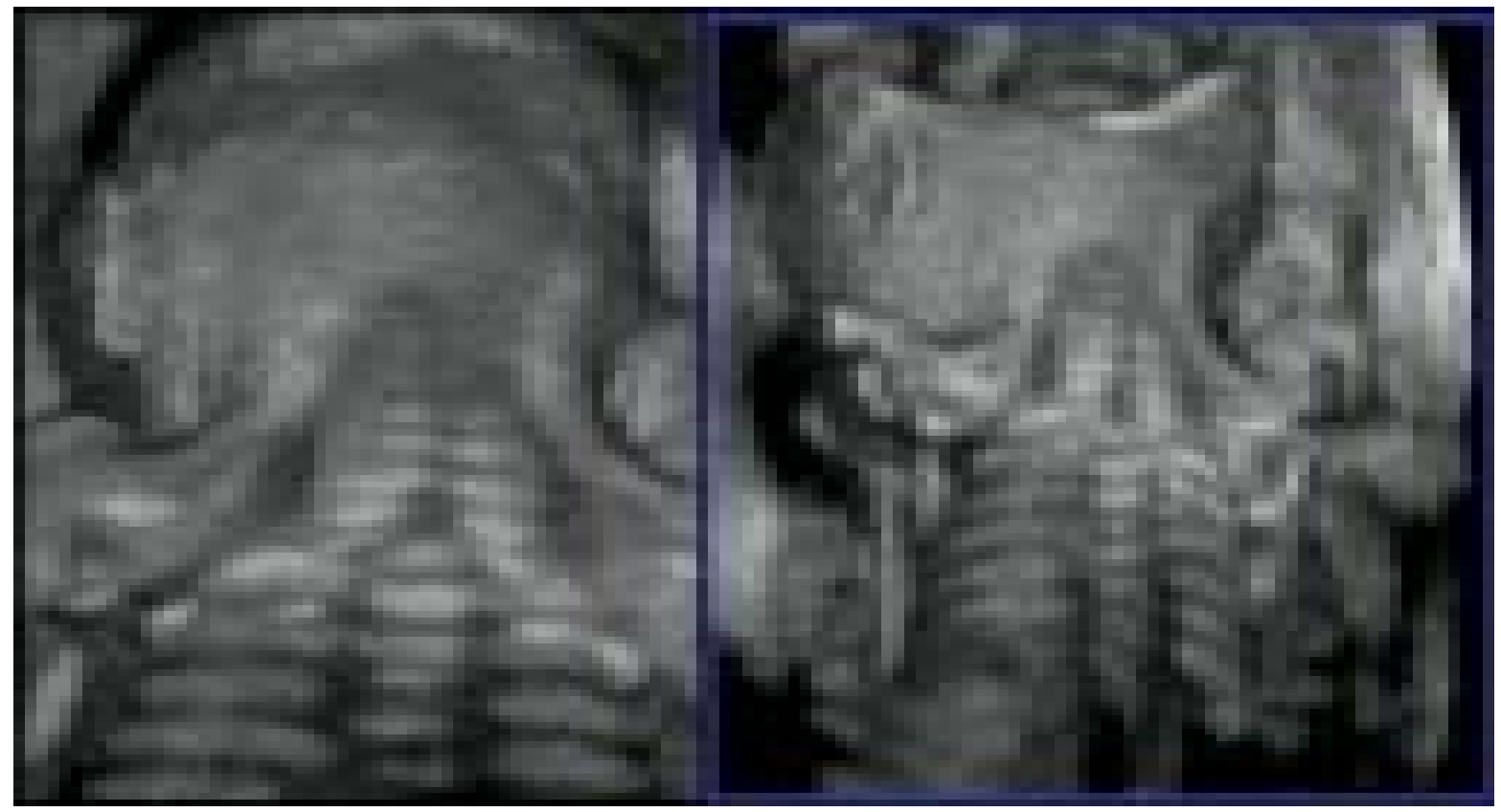

Fig. 9: 4D study of axis and atlas

described that the three orthogonal planes proved to be most helpful delineating the exact nature and anatomic level of the defect and that 3D reconstructions clarified and documented the true magnitude of the defects. Dyson also set a high valuation on planar images derived from 3DUS volume data sets generally in the viewpoint of diagnostic purposes, whereas rendered 3D images were more useful as a point of reference and were better appreciated by patients in understanding fetal abnormalities Recent advances in 3D technology with higher resolution imaging, has contributed to more comprehensive 
and precise evaluation of the spine and vertebra. BonillaMusoles and Blaas reported the first cases of spina bifida as early as nine weeks. Lee and colleagues evaluated spina bifida and described that the level of the defect on 3D images correlated well with those on 2D images and postnatal imaging studies. They concluded that 3D multiplanar views were more informative than rendered views for localizing bony defects of the fetal spine, and that this approach added diagnostic information complementary to the initial assessment by 2DUS. Pooh also used 3D ultrasound equipment for prenatal accurate diagnosis of the fetal CNS abnormalities

Transvaginal 3D sonographic approach was useful for screening and evaluation of fetal spinal/vertebral lesions in the first half of pregnancy.

Of course, in cases with spina bifida, the existence of Chiari type II malformation, secondary hydrocephalus or ventriculomegaly and deformity of lower extremity such as clubfoot should be confirmed by sonography. Biggio investigated the natural history of disease progression in utero in cases with open spina bifida and described that most cases develop ventriculomegaly, and the majority do so by 21st week of gestation and that fetuses that develop ventriculomegaly later in gestation have less severe ventricular dilation at birth.

\section{Neuroimaging of Normal Vertebrae by 3D Ultrasound}

Demonstration of spine and vertebrae by 3D ultrasound includes three orthogonal views and reconstruction of bony structure. Figs 6 to 9 show three orthogonal view and 3D reconstructed image of normal fetuses. Movement of region of interest provides $3 \mathrm{D}$ reconstruction image of the surface level, neural arch level and vertebral body level. The same Figures 6 to 9 show the changing appearance of vertebral bony structure between 9th and 22nd week of gestation. Transvaginal 3D transducer was used. By 13th week of gestation, vertebral bodies and intervertebral spaces and bilateral premature vertebral arches are clearly demonstrated. Until 15th week of gestation, bilateral laminae are completely apart at all vertebral levels and this condition is called 'physiological spina bifida.' At lumbosacral level, the distance of the median opening between bilateral arches is wider than at thoracic level. At 16th and 17th weeks, the right and left laminae grow toward a median line and closely approach each other at the thoracic level but are still clearly separate at the lumbosacral level, and thereafter, gradual approach is seen. At 18th and 19th weeks, lumbosacral vertebral laminae still separate each other in a median line, but before 23rd week of gestation, gaps between bilateral laminae at lumbosacral levels are almost closed (Pooh).

Vertebral column malformations are likely to have adverse sequelae or structural deformities that usually have a devastating effect on the quality of life. Spinal defects with marrow externalization are among the most difficult malformations to diagnose, requiring considerable experience.
Many of these defects and anomalies are diagnosed well into the second and third trimester with 20 , frequently as a result of abnormally elevated maternal serum alpha-fetoprotein (MSAFP) levels. Consequently, the majority of cases go unnoticed in routine prenatal ultrasound check-ups.

However, ultrasound diagnosis can be very difficult during the first half of pregnancy. Frequently, an experienced ultrasonographer is needed to identify the subtle markers of medullar canal defects, which are often only found through the detection of indirect signs (polyhydramnios, hydrocephaly, banana sign, lemon sign, strawberry sign, etc.). Even the experienced eye at times may not readily detect small defects, or defects located in the inferior part of the lumbosacral region.

Currently, the combination of US and MSAFP are considered the "gold standard" for the diagnosis.

\section{Etiology and Classification}

NTDs are malformations, starting early in pregnancy, that result from either a failure to close, or a defective closure of the neural tube during the fourth week of embryonic development.

The most severe form of failure, craniorachischisis, is a lack of closure along the entire length of the medullar canal, of which a 3D description already exists 23. It occurs when the brain and neural tube have not completed the neutralization process, remaining open.

The mildest form is spina bifida occulta, which has also been reported with 3D. Spina bifida occulta, although no less dramatic than the other forms, is a spina bifida resulting when the two halves of the vertebral arch fail to fuse. This is referred to exclusively as a bone defect and not as a marrow protrusion.

Neural tube fusion starts in the area of the fourth somite and extends cephalad and caudad. Failure of primary closure results in upper-tube defects frequently associated with severe cephalic-pole defects, while low thoracic, lumbar, and sacral defects result from failure of secondary closure. The most frequent location is in the lumbosacral region ( $60 \%$ of cases), followed by thoracolumbar (36\% of cases), and sacral (4\% of cases) (Fig. 10).

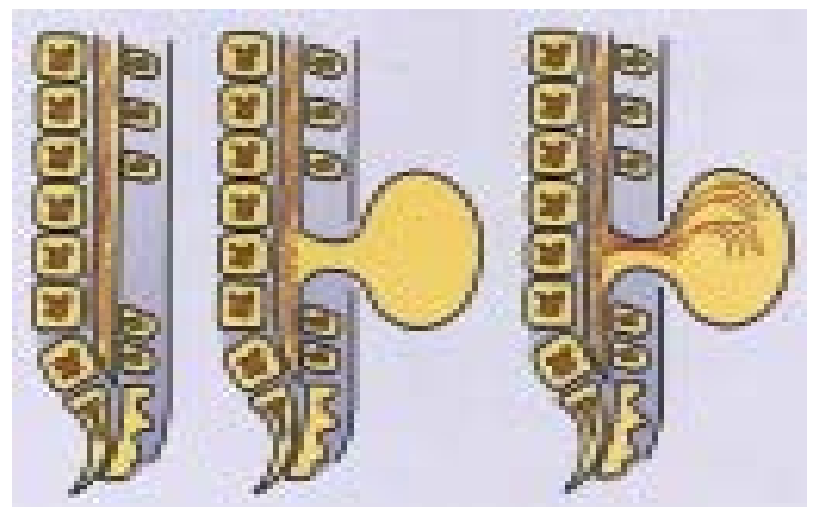

Fig. 10: Prime locations of NTDs 


\section{Current Classification}

NTDs have been divided into the following:

- Hidden spina bifida

- Open spina bifida:

- Partial and complete rachischisis.

- Cystic spina bifida (Fig. 11):

- Meningocele

- Myelomeningocele

- $\quad$ Myelocele (Fig. 12).

\section{Ultrasound Diagnosis}

Using US, and especially 3DUS, the spine is identified from week eighthon, and the spinal canal from week 10th on. Nevertheless, and with some exceptions, these defects are difficult to observe before week 16th (Figs 12 to 22).

With transvaginal 20, the dorsal ossification nuclei are observed as two parallel echogenic lines separated by a narrow space that widens somewhat in the axis and atlas region. The three ossification nuclei surrounding the spinal marrow, two posterior and one anterior, are visualized in transversal sections.

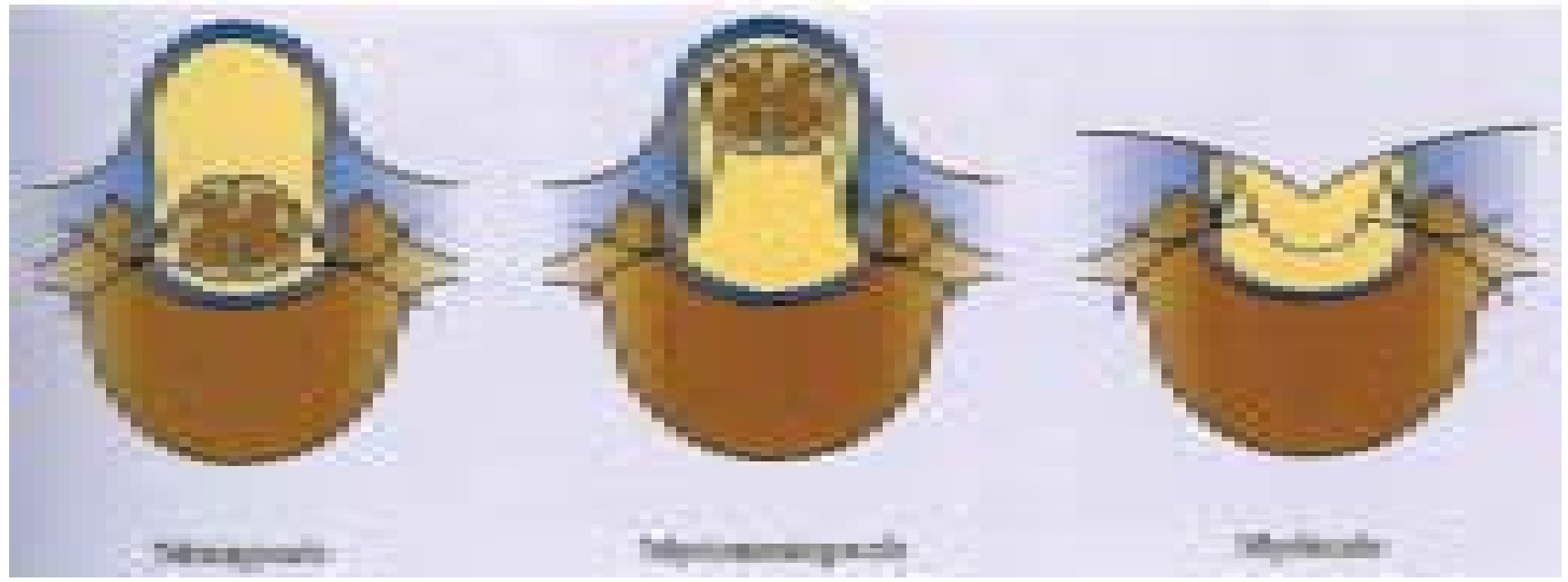

Fig. 11: Types of cystic spina bifida

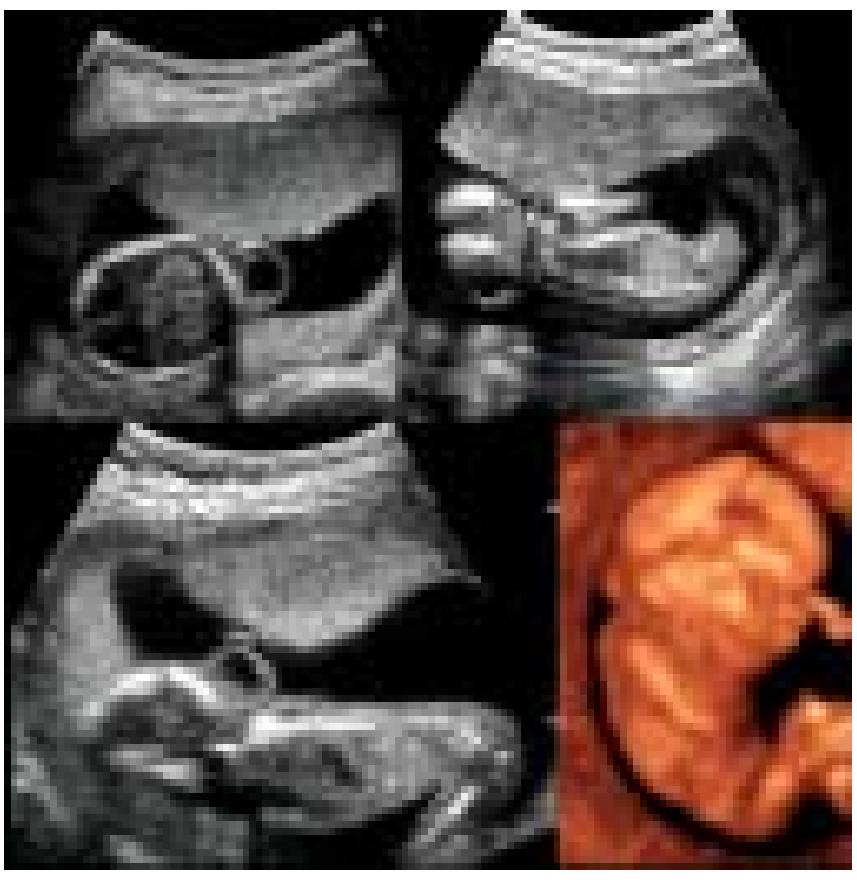

Fig. 12: Early detection of a very high neural tube defect observed in week 14th. Cervical open neural tube defect affecting axis, atlas and cervical vertebrae

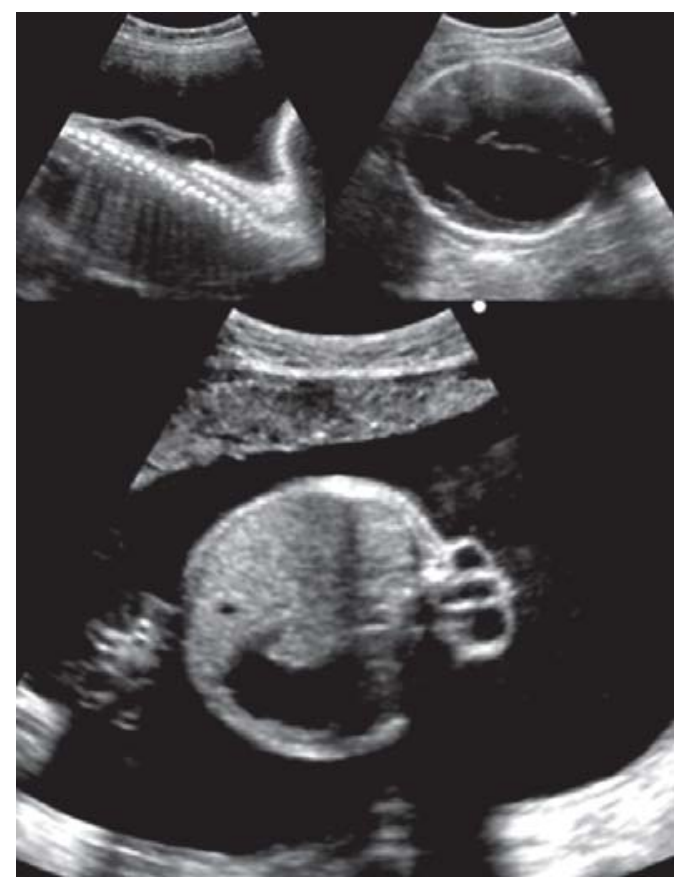

Fig. 13: Myelomeningocele: This is the typical view. The fetus has also an hydrocephaly 
Machado LE et al

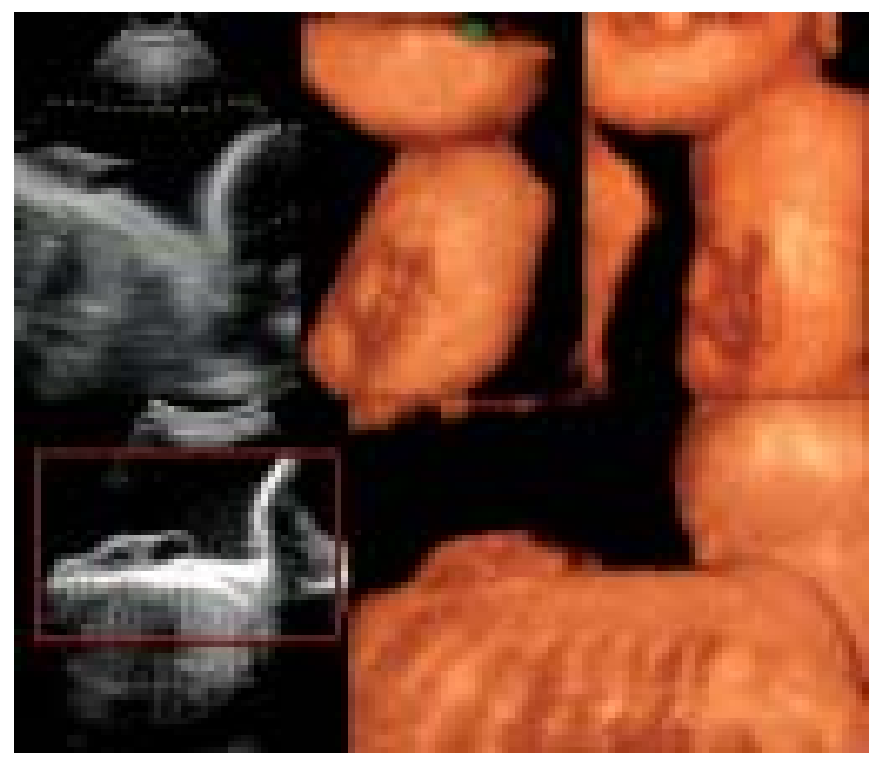

Fig. 14: Comparison between 2D and 3D visualization of a high located open spina bifida

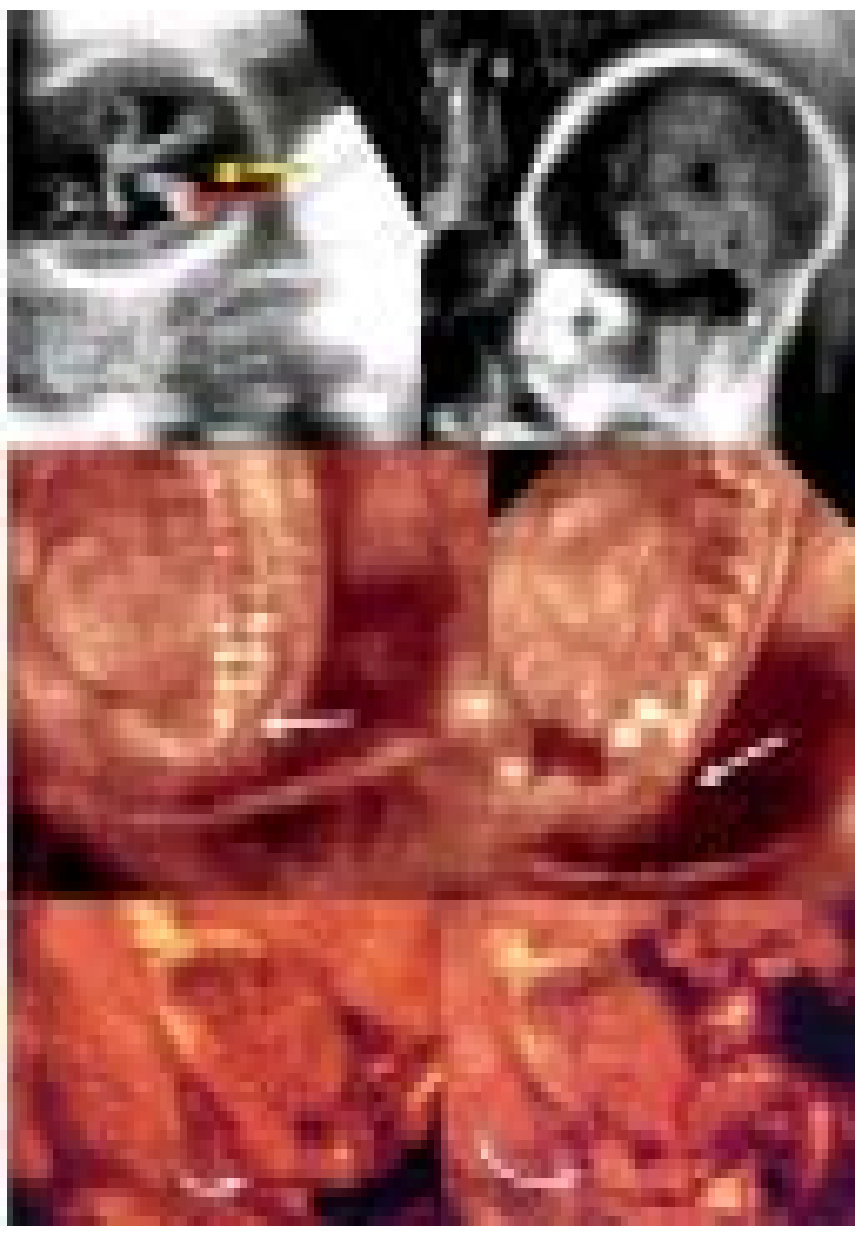

Fig. 15: A very small lumbosacral myelomeningocele, the most common. Although its small size it is associated with hydrocephaly

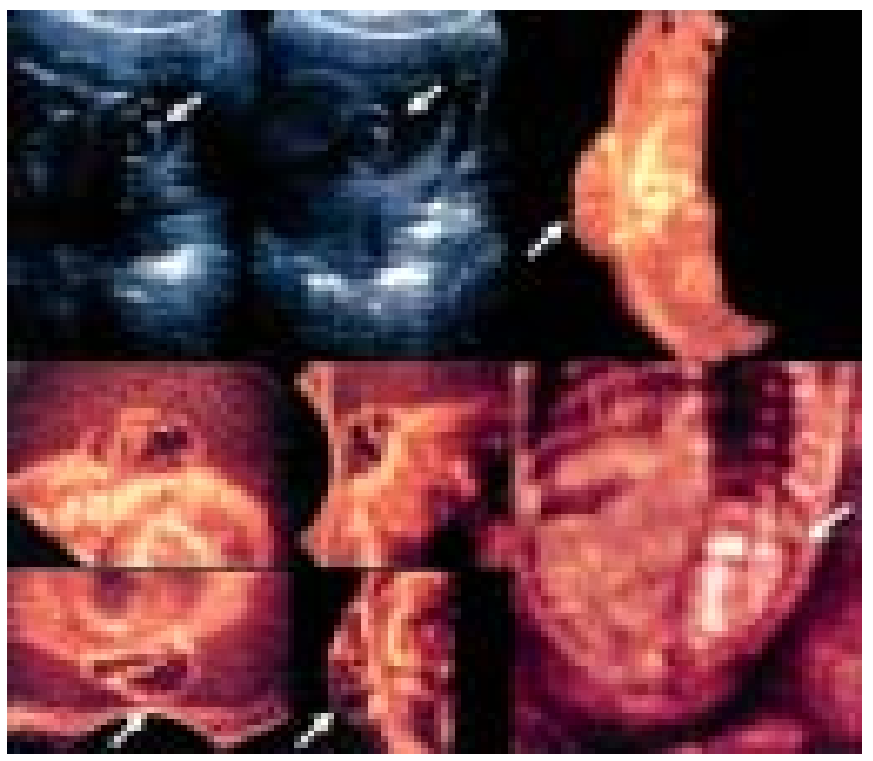

Fig. 16: Lumbosacral myelomeningocele lumbar, the most common, observed using maximum transparency and X-ray modes

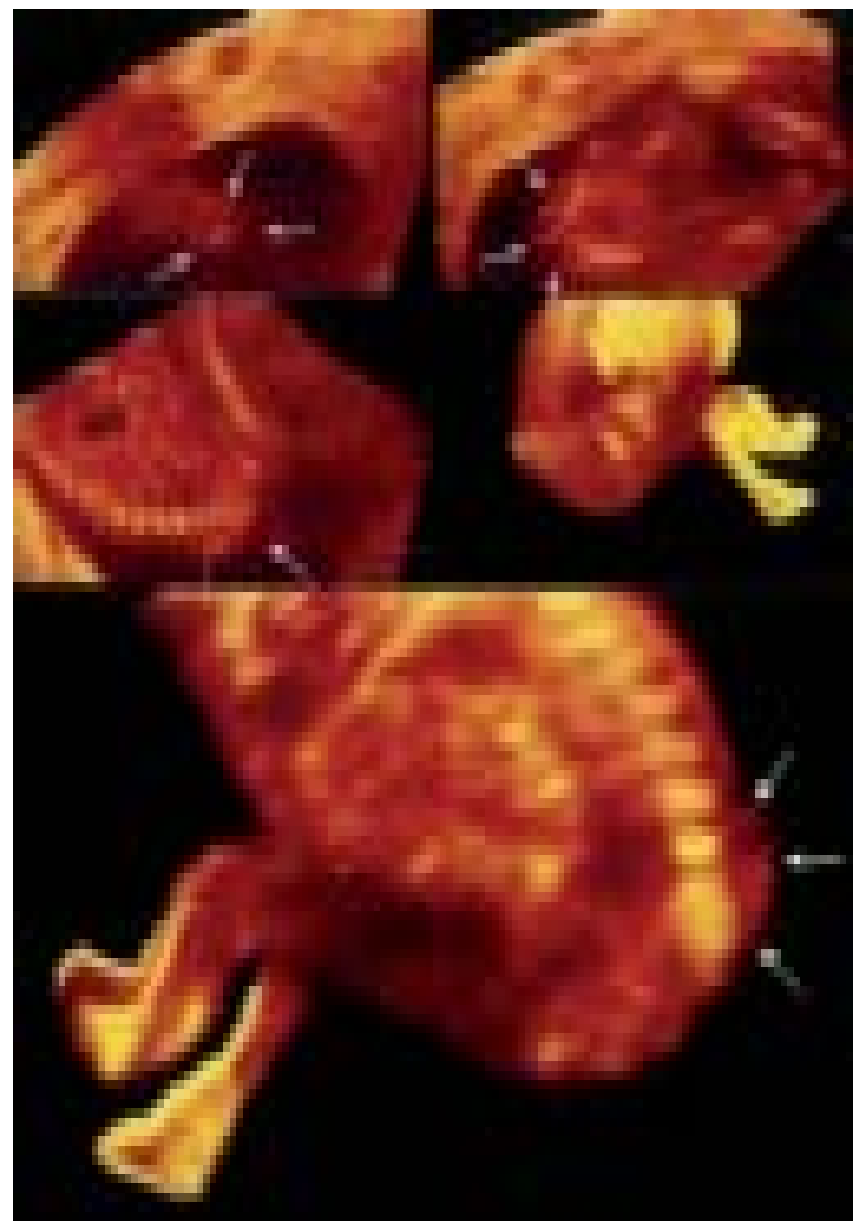

Fig. 17: A very small myelomeningocele 


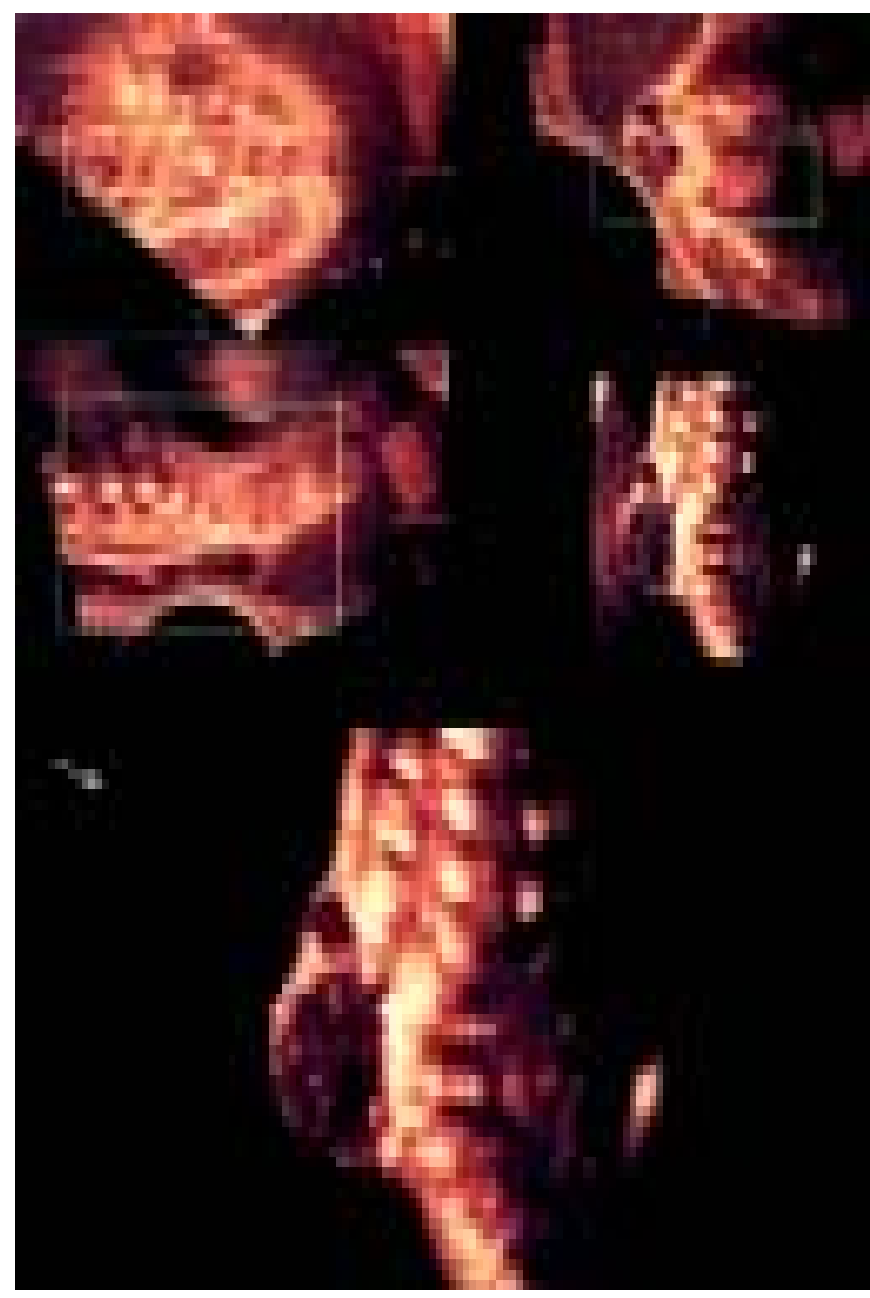

Fig. 18: Lumbosacral myelomeningocele studied only with X-ray mode
Only 30 allows the visualization of the whole medullar canal, this being one of its advantages.

Ultrasound diagnosis of NTDs should include the following parameters, as well, as a predictive value for bad perinatal outcome:

l. Identification of the defect, localization, extension, and degree of opening.

2. A search for associated CNS lesions. More than 50 percent are associated with hydrocephaly, banana, lemon, and strawberry signs.

3. A search for associated lesions besides CNS lesions.

4. An estimate of the neurological and functional consequences of the defect by observation of limb movements, presence of polyhydramnios, skull or brain abnormalities, and involvement of other organs.
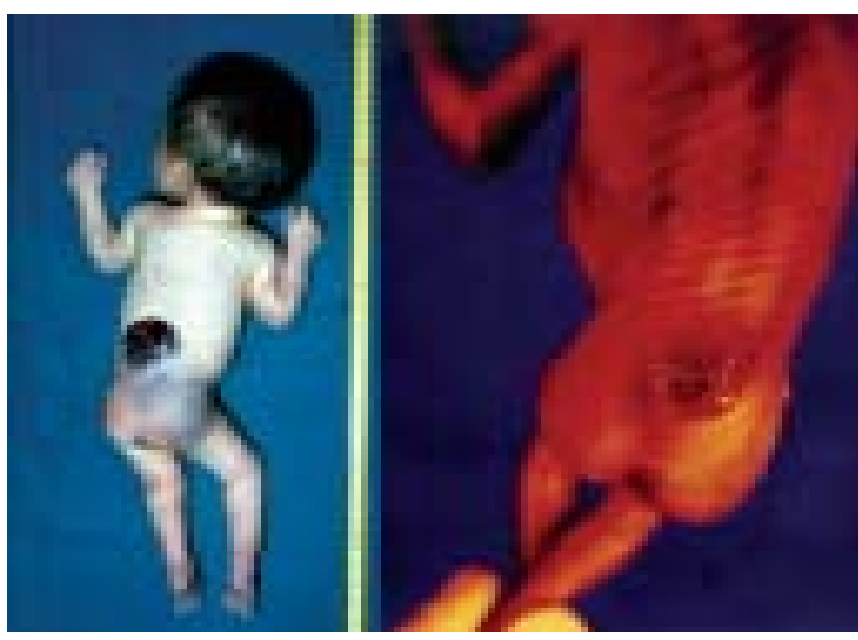

Fig. 19: The case showed in Figure 18

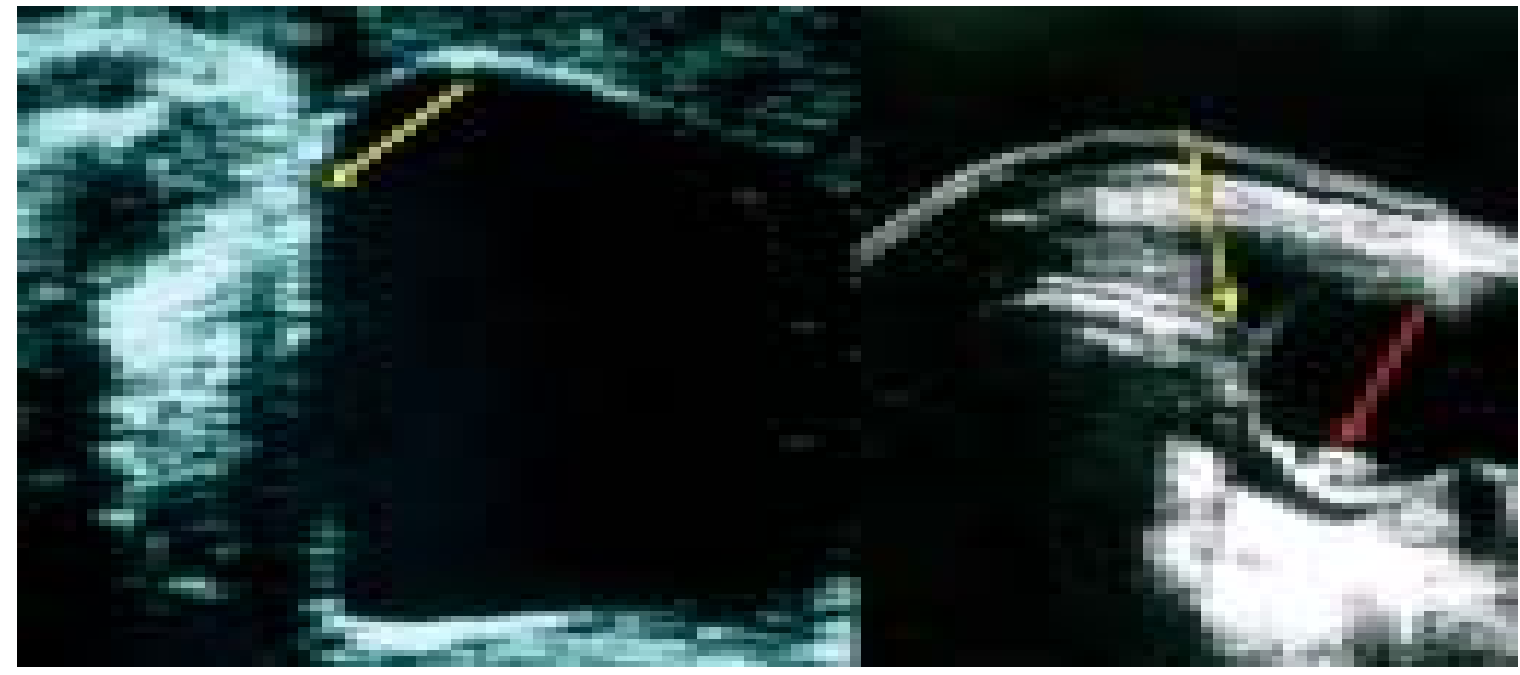

Fig. 20: Old cases of myelomeningoceles showing a very bright cyst (left) and with medullar tissue (right, red arrows) 


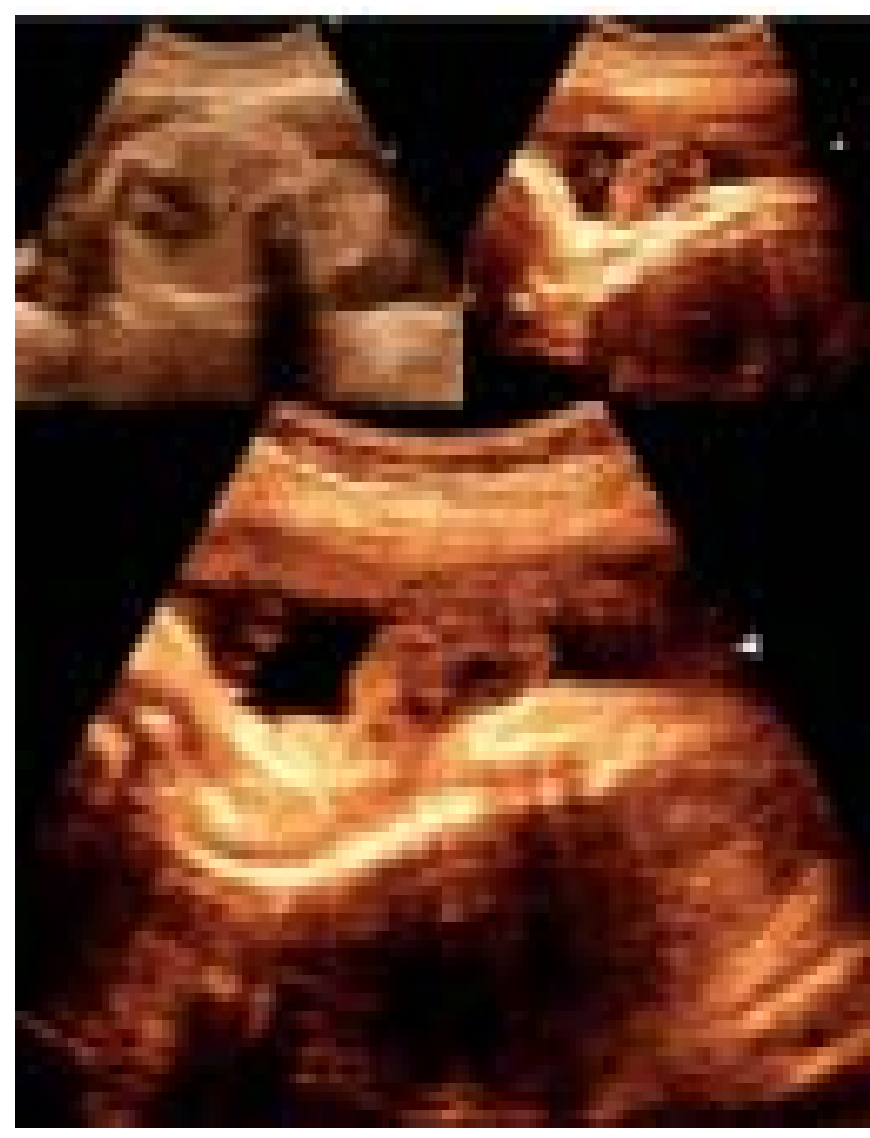

Fig. 21: Myelomeningocele alto. This is an uncommon finding

In order to identify NTDs, especially minor defects, it is of help to observe transverse cuts of each vertebra in the different sections of the vertebral column. Ideally, each vertebra should be visualized. However, with large defects, or with small defects in fetuses in the dorsal anterior position, axial cuts are preferable.

Meningocele results when the posterior neural arch fails to fuse and the herniated sack does not contain neural tissue. This defect is commonly associated with other malformations. In myelomeningocele, the most frequent open NTD, the herniated sack does contain neural tissue.

The most frequently associated CNS malformation, accompanying 50-75 percent of the cases, is ventriculomegaly, and hydrocephaly in its most severe forms. Occasionally, this is the first detected anomaly which prompts the study of the spine and leads to the diagnosis.

Arnold-Chiari syndrome is nearly always accompanied by ventriculomegaly. This defect consists of a posterior brain injury characterized by the displacement of a small portion of tissue from the cerebellar vermix. The displacement, in turn, causes the marrow and fourth ventricle to descend. Associated symptoms are typically neuromuscular, affecting the newborn's capacity to walk and retain urine. The most severe cases result in clubfoot, hip luxation, and paralysis of the lower extremities.

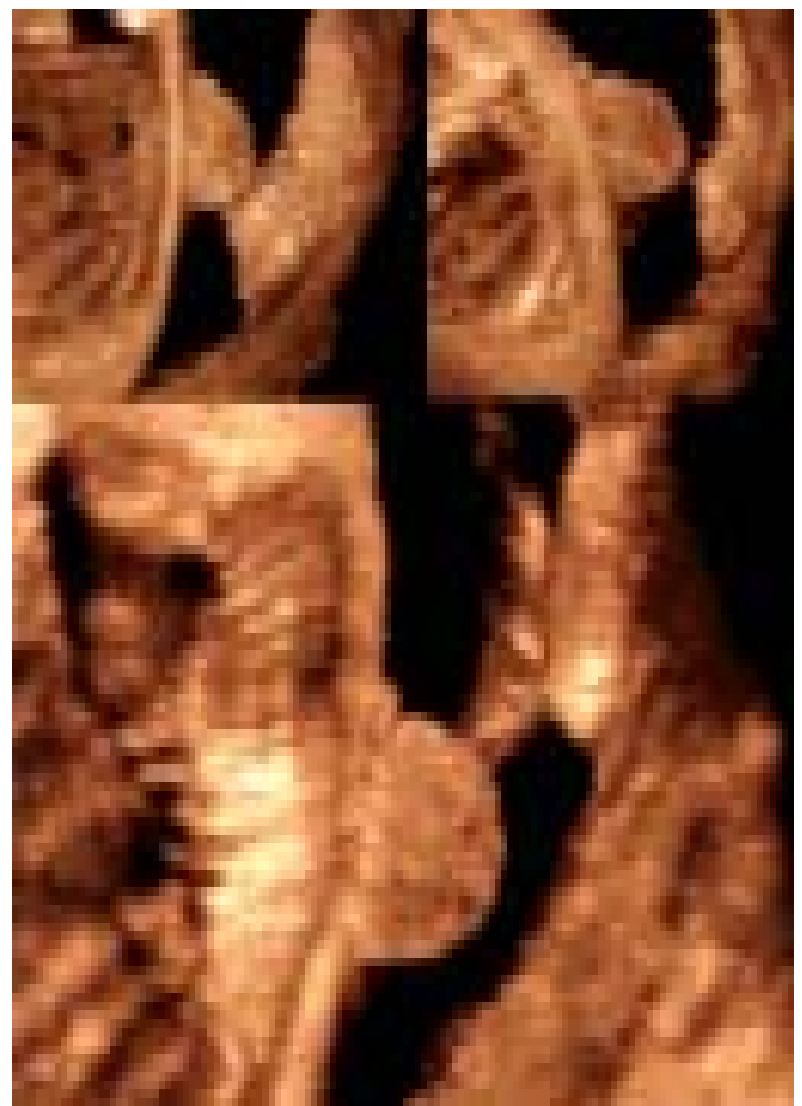

Fig. 22: High located myelomeningocele. 3D picture of Figure 21

Although all NTDs have a poor prognosis, those located in the sacral regían have shown relatively promising results in regards to ambulation when diagnosed intrauterine and when a pediatric surgery team is ready after birth. Nevertheless, urinary incontinence will affect 100 percent of cases. In our experience, these are one of the most difficult malformations to diagnose with 20, and often the diagnosis comes either to a late or at birth.

Three-dimensional US provide early and complementary information that helps establish the precise level and extent of the defect. Our experience suggests that the complicated and time-consuming 20 examination can be facilitated by observing the whole vertebral column in surface and transparency 30 modes, and by studying the fetal behavior and motility with 40 . When orthogonal planes with 30 rendering are used, a welldefined spatial image of high resolution can be obtained. We suggest that the major reason for using $3 \mathrm{D}$ is to precisely determine the level and extent of NTD lesions initially seen with 20, and that 3D may also help establish a definitive diagnosis when elevated MSAFP levels and inconclusive 20 scans suggest the possibility of NTDs. 


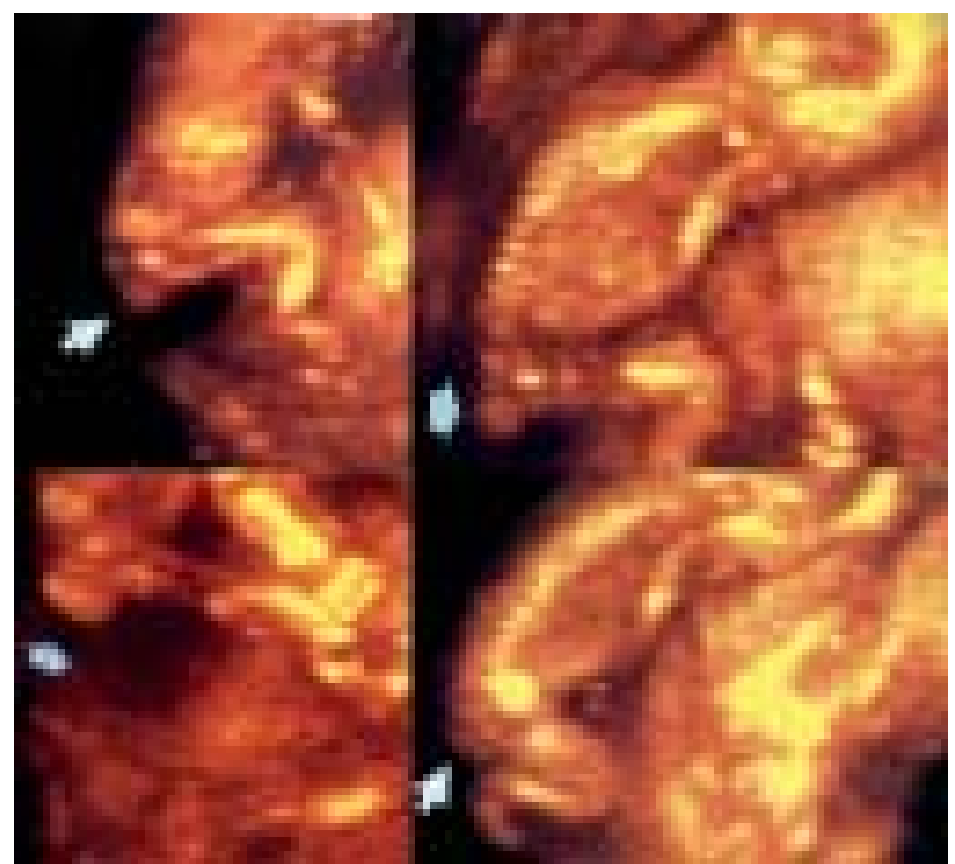

Fig. 23: The arrows show a small teratoma starting in the sacral bone

\section{SACROCOCCYGEAL TERATOMAS}

Fetal tumors are difficult to evaluate prenatally. They may appear in virtually any fetal organ. However, the most common, the sacrococcygeal teratoma (SCT), represents more than half of all. Their incidence is one in 40,000 births.

There are several reports of prenatal diagnosis of SCTs with 2D, but reports of diagnosis with 3D are rare.

The course of SCTs diagnosed on routine sonography is associated with a higher -than-expected incidence of prenatal and perinatal complications. Since prenatal determination of prognosis, time of delivery, and mode of delivery, depend on an accurate assessment of the extent of tumoral involvement with the sacrum and other pelvic organs, our primary focus is to determine whether the addition of 3D to conventional 2D improves the prenatal diagnostic accuracy of SCT.

Besides guiding prognosis, serial ultrasound scans may allow the mode of delivery to be planned more effectively.

Most extragonadal teratomas derive from more than one of the primitive germinal layers, and usually contain histological elements of all three. They are of variable size,

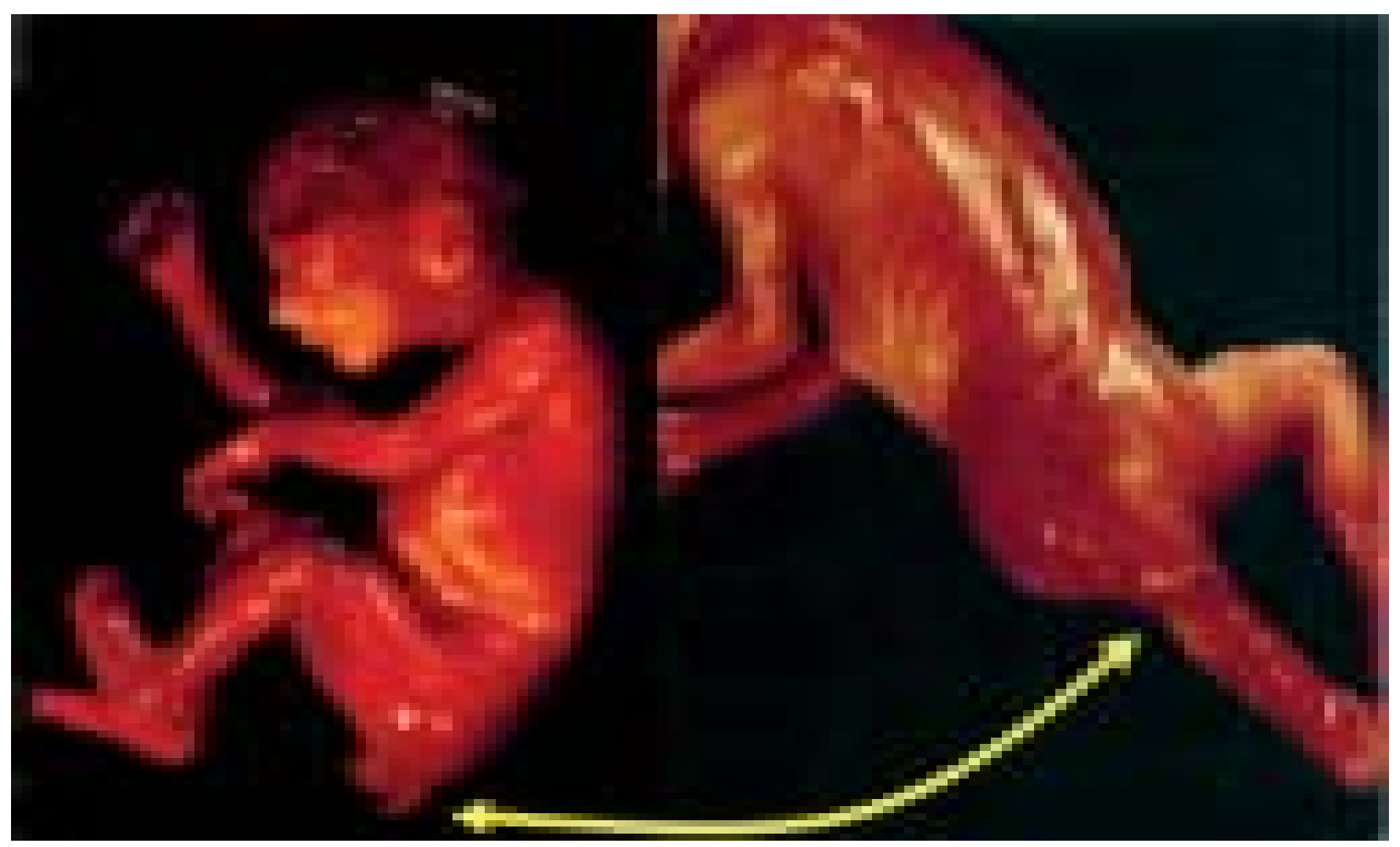

Fig. 24: Small teratoma (Figure 23: Newborn) 
but most of those diagnosed prenatally are large, mainly because they are fast- growing and that are usually diagnosed late.

Approximately 80 to 85 percent of external fetal teratomas are benign. Similarly, 5 to 20 percent of partial or complete fetal intrapelvic tumors are malignant.

Sacrococcygeal teratomas arise from the anterior surface of the sacrum or from the coccyx. The focus of origin is usually their only point of attachment.

The localization of teratomas is related to their cells of origin. The sacrococcygeal ones originate from pluripotent cells of Hensen's nodule, the anchorage point of sexual cells. They are thus related to germinal line cells (Boveri's Keimbahn). The tumours are histologically classified as:

- Mature teratomas,

- Immature teratomas, and

- Embryonic carcinomas with or without teratomas.

It is not possible to definitely distinguish between them with sonography.

Histologically, they contain squamous epithelium and other skin elements, neuronal tissue, fat, mucus, striated muscle, cartilage, and sometimes bone and mandible structures.

It has been suggested that these tumors are abortive forms of twinning. The occasional presence of organ-like elements, and the impression that the twin index in the families is higher than average, support this idea.

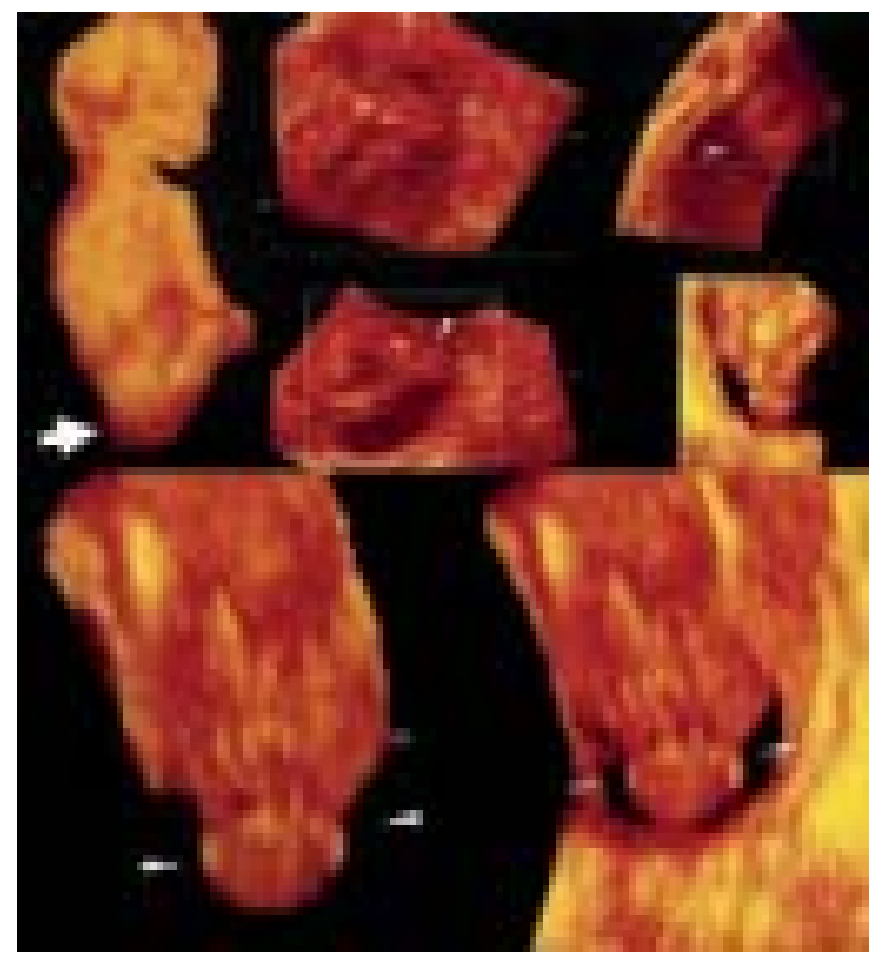

Fig. 25: 3D view of a small teratoma but with wide sacral implantation. The prognosis is worthier than the one in figure
Sacrococcygeal teratomas are usually external tumors with variable intrapelvic extension. However, they can be completely intrapelvic without any external manifestations.

The structures most frequently affected are the terminal bones of the medullar channel. These are most frequently associated with the worst prognosis. Although many of these affect large portions of the sacrum and coccyx, there are occasional cases in which these bones are minimally affected, with excellent postnatal surgical prognosis (Figs 23 to 27).

The management of SCT is by planned delivery and postnatal surgery, especially with presentation after 30th week of gestation.

Fetuses with tumors that appear in the second trimester have a poor prognosis. In these cases the tumors can grow rapidly and develop arteriovenous communications that result in placentomegaly, fetal hydrops, and fetal demise. Inadequate placental flow may induce the release of vasoactive substances that can gain access to the maternal circulation, result in endothelial cell injury, and lead to maternal toxemia. This is also known as maternal mirror syndrome and as Ballantyne syndrome, in which there are signs and symptoms of pre-eclampsia such as hypertension, proteinuria, peripheral edema, pulmonary edema, nausea and vomiting.

Early prenatal diagnosis of SCT is important since mortality is inversely related to the gestational age at which the diagnosis is made. The later the diagnosis is made, the worse the prognosis.

It is possible to determine the localization and size of the SCT along with the degree of involvement of intrapelvic structures using sonography. A few reports indicate that these tumors can be identified accurately with $2 \mathrm{D}$ even at the beginning of the second trimester.

Most SCTs are solid or solid-cystic tumors. Only 15 percent are purely cystic. The cases reported here were of the solid and solid-cystic varieties. Cystic tumors and tumors with cartilaginous or osseous elements are more likely to be benign (Figs 26 and 27).

The likelihood of malignancy is increased up to 70 percent if the uterine size is larger than expected for gestational age, due either to a large fetal tumor or to the presence of polyhydramnios. In these cases, polyhydramnios results from transudate from the tumor, arteriovenous fistulas, or from intratumoral hemorrhage.

The ultrasound image is of a heterogeneous mass attached to the fetal buttocks that can be solid, cystic, or mixed. The mass may be dense and of variable size and have echo-dense areas, with acoustic shadows, that suggest calcification (Figs 23 to 27$)$.

If the tumor is external, the differential diagnosis includes myelomeningocele along with other caudal entities. If the location is internal, the differential diagnosis includes meconial cysts, ovarian cysts, hydrocolpos, bowel dilatation or duplication, mesenteric cyst, bladder duplications, or cystic 


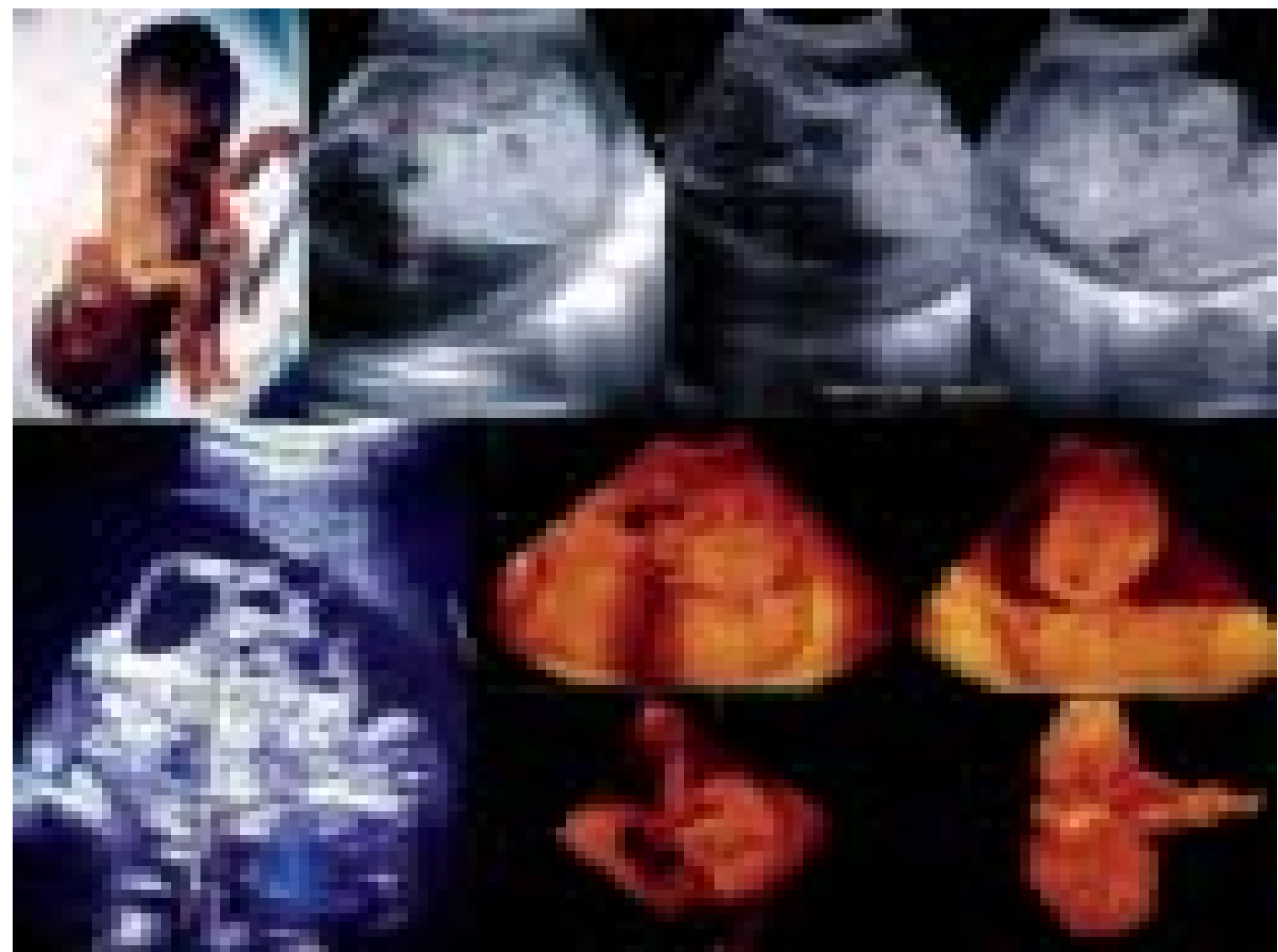

Fig. 26: 2D and color Doppler of a great teratoma. The tumor has solid-cystic components, it is well vascularized. Its growth potential is strong. 3D orthogonal planes and rendering of the tumor. It is evident that the implantation area is very width and includes the sacrum and the coccyx

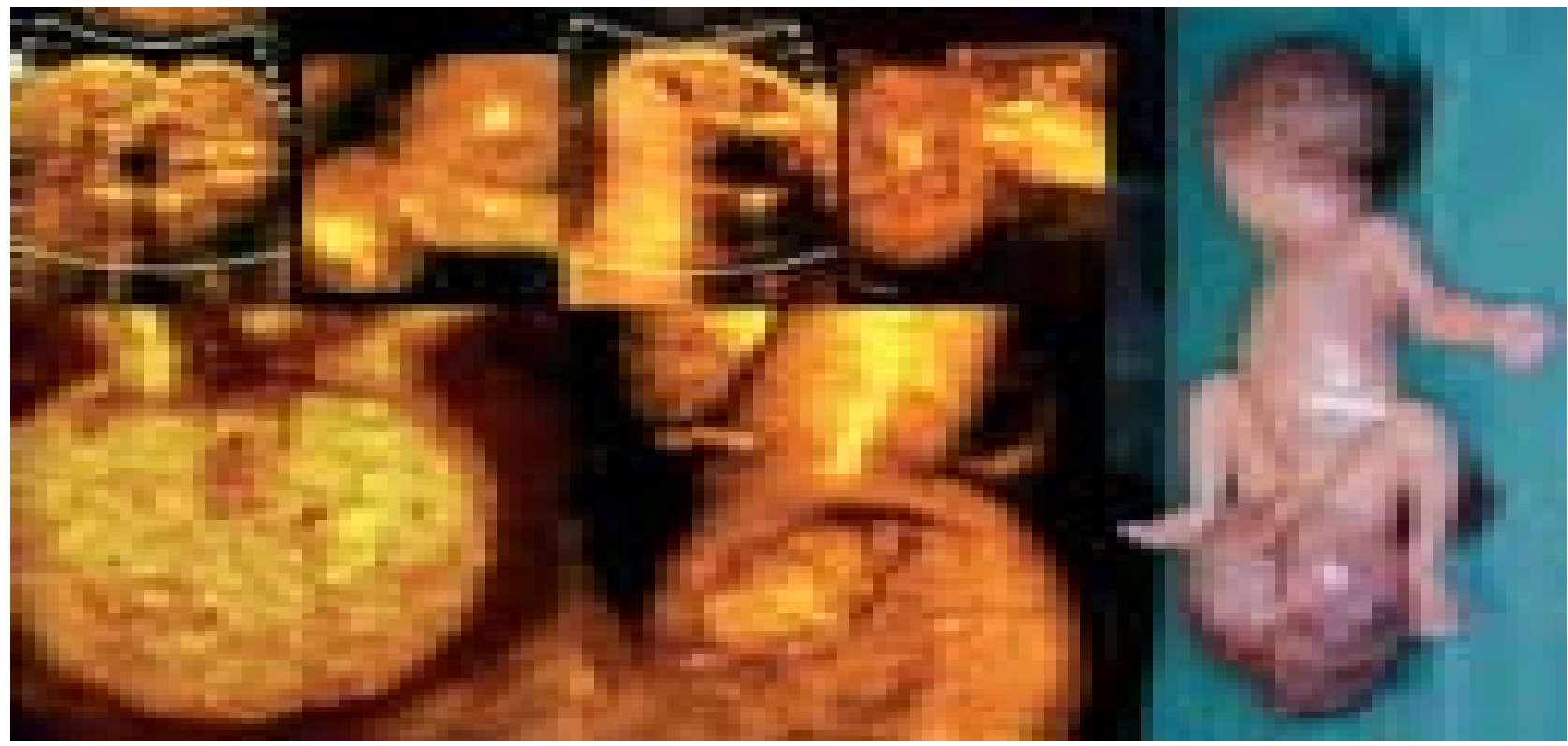

Fig. 27: 3D multiplanar view of another very big and solid teratoma.

Fetal breach with arising tumor is clearly depicted. The whole sacrum, internal pelvis and gender are affected 
neuroblastoma. If the tumor is solid, the differential diagnosis includes chordomas, neurogenic tumors, lipomas, hemangiomas, and malignant melanomas.

Other ultrasound signs include the presence of hydrops and changes induced by mass compression such as bladder displacement, urethral obstruction, and hydronephrosis. In one of our cases the tumoral mass distorted the female genitalia so that they appeared ambiguous (Figs 26 and 27).

The basic ultrasound evaluation of the vertebral column and caudal region should to be taken in account. Although there are no differences in vertebral column length when measured with $2 \mathrm{D}$ or 3D, the latter modality allows a more complete diagnosis because of a clearer visualization of the caudal region and a better outline of the bony areas, thanks to the transparency modes available with 3D (Figs 23 to 27).

These advantages of 3D make it easier to define SCTs and distinguish them from other clinical entities. The possibility of rotation and removal from view of interfering structures with 3D allows detailed observation of the dorsal part of the vertebral column in those cases in which it is difficult or impossible to clearly see these areas with $2 \mathrm{D}$.

Recent reports suggest that magnetic resonance imaging (MRI) is capable of providing high-resolution images in a short time, and is particularly useful in enabling a better contrast between the cystic and solid components. It has been reported that an ultrafast T2- weighted imaging method enabled clear visualization of morphological details of the fetus without motion artefacts.

Although MRI provides excellent visualization of SCTs, and some reports suggest that it may even be superior to $3 \mathrm{D}$, our experience suggests that $3 \mathrm{D}$ is a valuable complement to 2D since it improves diagnostic accuracy with SCTs as well as with other fetal malformations.

\section{CAUDAL REGRESSION SYNDROME}

Caudal regression syndrome, of which sirenomelia is the more severe, is formed by a group of anomalies that associates vertebral agenesis, genitourinary and digestive malformations. Malformations can vary from anal atresia to sacral/lumbar or thoracic vertebrae defects.

It has been associated with mistreated maternal diabetes mellitus, given that the medial-posterior axis of the mesoderm is affected in these patients.

Even though some cases of this syndrome have been found to be of inherited nature, most appear de novo and the risk of recurrence is less than 3 percent.

\section{Sirenomelia}

Sirenomelia or mermaid syndrome is an extremely infrequent malformation, occurring in one out of 60,000 newborn, and is more frequent in males than in females (3:1).
It has been described as the most severe form of caudal regression syndrome. However, recent studies categorize it as a separate nosological entity.

Even though its aetiology is unknown, it has been associated to maternal diabetes, cocaine consumption during the first month of gestation or exposure to high doses of etretinate or cyclophosphamide; these last two substances were confirmed after experimenting with animals.

\section{The Diagnosis}

The diagnosis should be suspected from echographic finding of oligohydramnios and bilateral renal agenesis during the second trimester. Its confirmation is not always simple, because the existence of a reduced amount of amniotic fluid (Figs 28 and 29). In fact, in some cases only bilateral renal agenesis could be diagnosed in uterus and sirenomelia only after delivery.

Recently, diagnoses have been reported from week 14th of gestation, using transvaginal sonography. Amniotic fluid was slightly reduced despite bilateral renal agenesis. This finding is not surprising, because at this gestational age amniotic fluid basically originates from the mother.

Severe oligohydramnion is a sonographic marker of renal agenesis or non-functioning kidneys in the second half of pregnancies. At week 16th, fetal urine production proceeds basically from glomerular filtration. The amniotic fluid proceeds from urinary production, respiration, deglutition, and fetal skin transudation. Before this week, the amniotic fluid originates in the amniotic membrane, blood and maternal transvasation. Nevertheless, even with a polyhydramnios, sonographic diagnosis is possible in the early-second trimester as shown in these and other reported cases.

It has been suggested that amnioinfusion improves prenatal diagnosis.

Morphologic alterations of lower limbs are of variable extension and are classified in three types, according to the number of feet during the diagnosis.

- Symelia apus: This is the most frequent type; the foetus has no feet, not even rudimentary ones; it has one femur, one or two tibial bones, and no fibula.

- Symelia unipus: There is only one foot, which can have up to a full complement of 10 toes; the lower limb has a pair of femur, as well as tibial and peroneal bones.

- Symelia dipus: Both feet are present, giving the foetus a mermaid-like appearance.

Lower limb malformations are associated with other skeletal or visceral anomalies. The most frequent are:

- Sacral agenesis.

- Anorectal atresia.

- Renal agenesis or renal cystic dysplasia.

- Internal and external dysplasia of the genitalia.

- Single umbilical artery. 


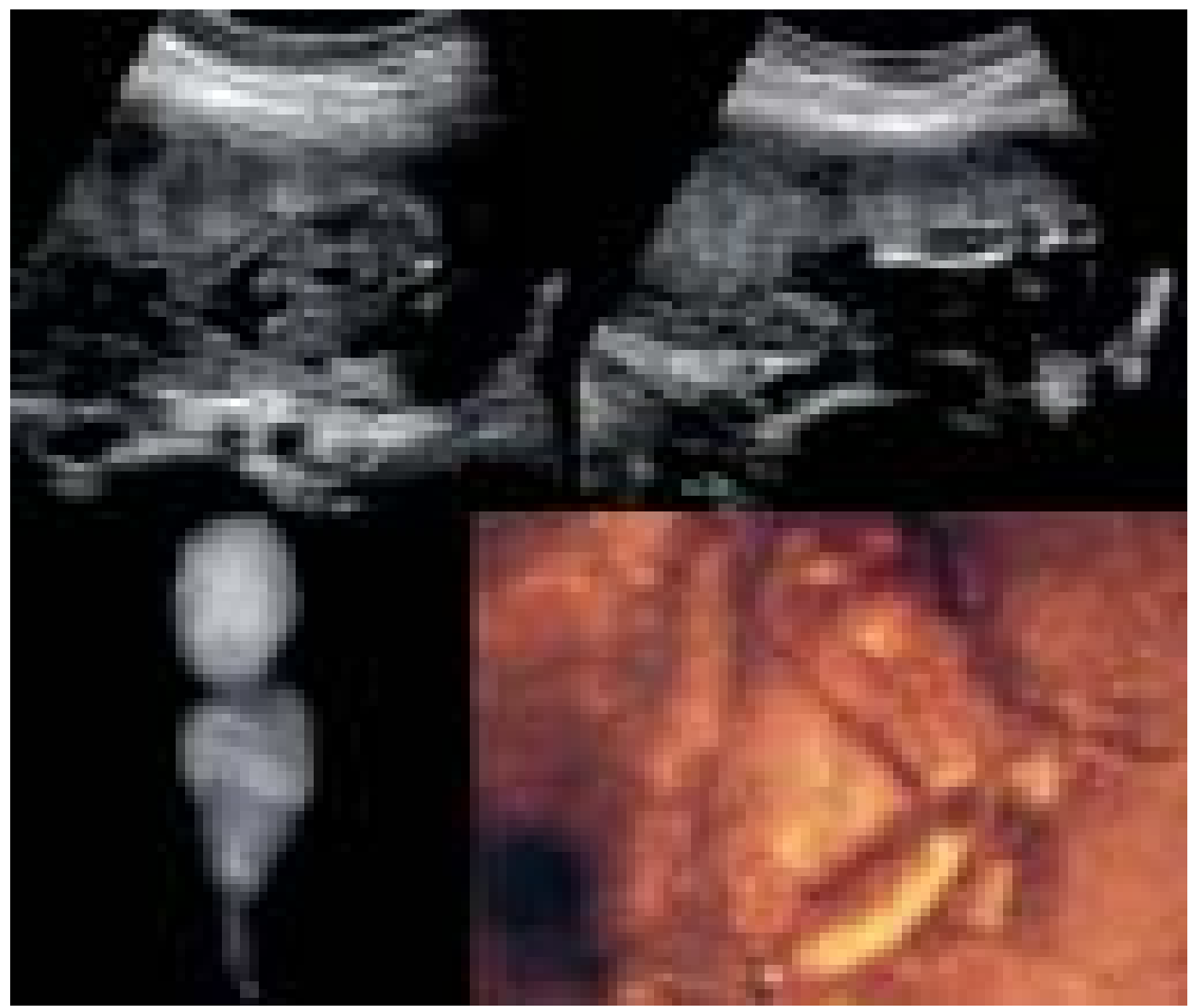

Fig. 28: 2D of the unique visible low extremity. Only one femur is observed. Gender and pelvic structures are no depicted. X-ray exam and 3D picture compare these findings with the newborn sirenomelia
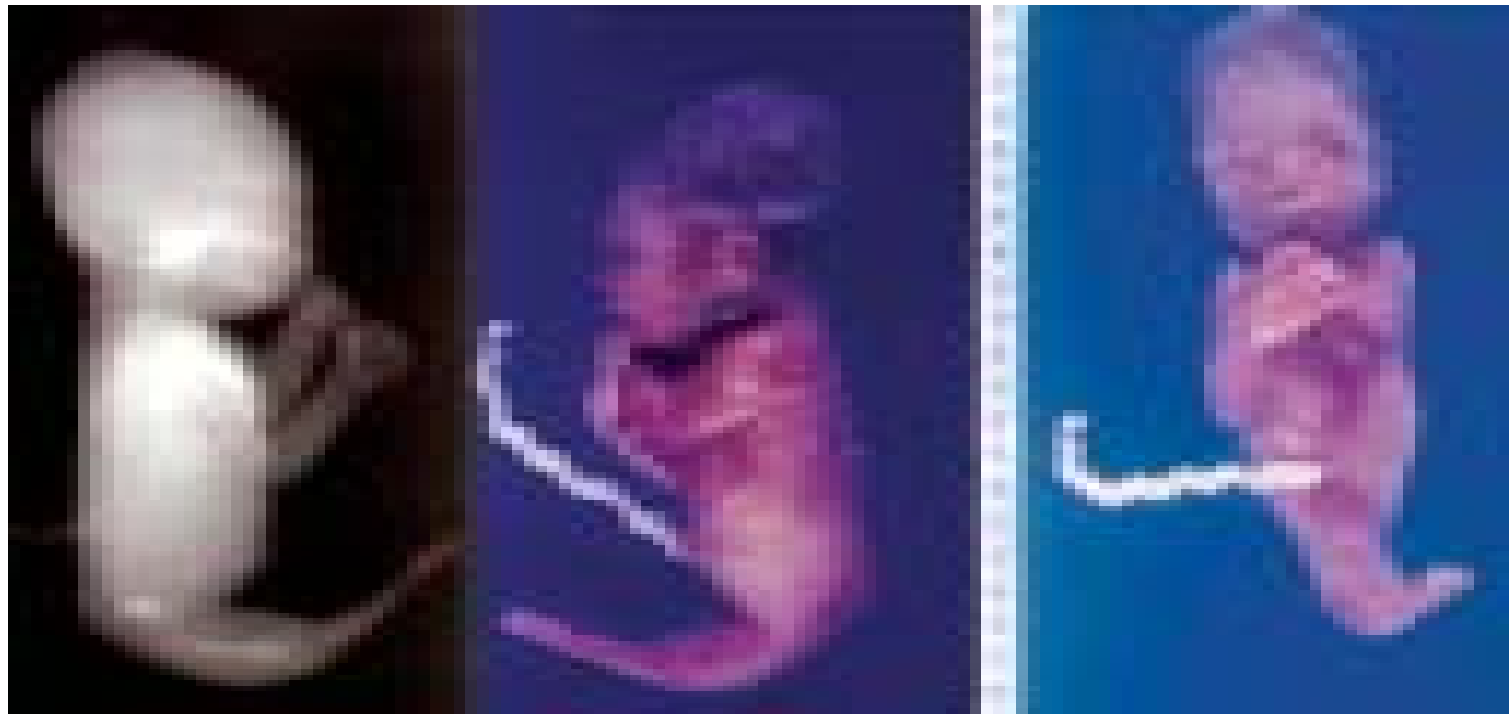

Fig. 29: Sirenomelia: Radiographic and newborn findings 
Other anomalies that are usually associated include cardiovascular malformations, abdominal-wall defects, severe scoliosis, and cerebral anomalies.

An early lesion in the caudal mesoderm has been suggested as the cause of this complex of malformation which affects the normal development of the foetus's lower limbs. An overdistension of the neural tube in this caudal portion could originate in the lateral rotation of mesoderm, causing fusion of the lower limbs, and closure of the gut and urethra. Experiments with mice exposed to high doses of retinoic acid have confirmed that there is an interference with the formation of mesoderm and its relationship with the pathogenesis of caudal digenesis.

Other proposals try to explain the defect by taking into consideration the accompanying vascular anomalies. Usually, there is a single umbilical artery, or one is normal and the other hypoplastic. These arteries come from the upper portion of the abdominal cavity; the vessels below this level are poorly developed. Therefore, tissues reliant on this hypoplastic vascular system do not have a normal development. It is suggested that the single lower extremity in sirenomelia is caused by the lack of separation between two lateral masses, rather than a fusion of the inferior limbs.

Prenatal diagnosis of the mermaid syndrome must be suspected in cases of renal agenesis, single umbilical artery, and lack of visualization of two femurs. The lethal prognosis of this malformation makes early prenatal diagnosis very important, although some published cases describe situations in which the foetus reached term with variable chances of survival.

\section{TWINS}

\section{Conjoined Twins}

It is likely that in the near future $3 \mathrm{D}$ will revolutionize prenatal diagnosis and that, combined with the 2D, it will be used systematically in any US examination, because it improves the diagnostic capability by 50 to 70 percent when compared with transabdominal and transvaginal 2D. In subtle malformations like nuchal translucency, phocomelia, ambiguous genitalia cleft lip and others, evidence is nowadays available.

The earliest detection and most accurate diagnoses will influence obstetric decisions and perinatal outcome. Conjoined twins are an example.

Conjoined twins are variants of monozygotic twin gestation that occur through incomplete dissociation of cells from the internal cellular mass between days nine and 13 of embryonic development (Fig. 30).

The incidence of conjoined twins varies between one in 50,000-100,000 deliveries, with the highest frequency observed in cases of multiple gestation resulting from the use of assisted reproduction technology. This incidence also seems to be higher in women during their later reproductive years than in younger women, presumably because of a thinner zona pellucida.

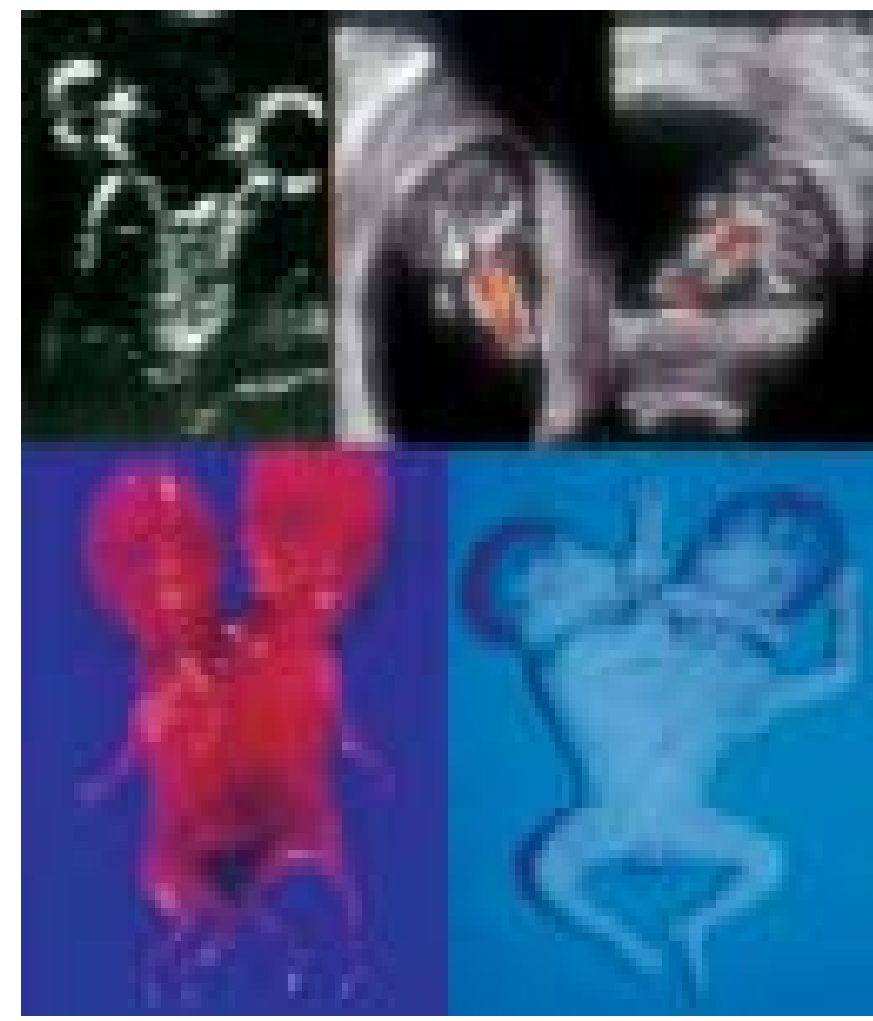

Fig. 30: Early diagnosis of conjoined twins using transvaginal 2D

With assisted reproduction technology, diagnostic studies are justified early in the first trimester for several reasons:

Those pregnancies have a higher incidence of multifetal gestation.

The incidence of fetal anomalies is higher with multiple gestations, especially if the twins are monozygotic.

In addition, there is a better chance of uncomplicated embryo reduction with early detection of fetal malformations.

\section{Etiology}

Monozygotic twins have a constant frequency estimated at 0.3 percent of all twin pregnancies. Except for certain known situations and some variants of assisted reproduction technology where it appears to be increased, this frequency is "relatively constant" worldwide.

The time of production of monozygotic twins has been traditionally linked to hypothetical mechanisms.

According to the latest knowledge, embryological division should occur shortly after fertilization, but before preimplantation, while the embryo is still within the zona pellucida. Also it has been suggested that twinning should occur shortly after blastocyst implantation. These theories, however, are debatable. 
The first hypothesis suggests that two divided embryos can remain within a zona pellucida. This suggestion was made before it was known that mammiferous embryos could be artificially divided into halves or fourths before compaction, and still survive. For this to occur, it is crucial to cultivate these embryos separately in different zona pellucida, with the aim of avoiding a subsequent aggregation and development of a simple chimera. This phenomenon occurs only in precompacted and compacted embryos and implies that the first theory is incorrect.

The second hypothesis suggests that events of division are rare following implantation. This has not been confirmed by subsequent observations.

Recent observations have concentrated on involving the zona pellucida in monozygotic twins. According to this theory, monozygotic as well as bizygotic twins are produced during hatching, when embryos are trapped in the opening of the zona pellucida.

Twins can continue to develop when the internal cellular mass is halved. This can happen when the trophoblast remains integral or when it separates. In the first case, monoamniotic, monochorionic twins will result, of which conjoined twins would be a variant, and would indicate a partial division of the internal cellular mass. This sets the time of most of these events on day six when the embryo does the hatching. For this reason, when artificial hatchings started to be done, conjoined twinning was entertained as a possibility. Alternatively, conjoined twinning can occur when there is incomplete cleavage in the embryonic disc between days 13 and 15 following fertilization (Table 2).

\section{Diagnosis}

Although most referred cases were diagnosed in the second and third trimester.

The Diagnosis can be made during the first trimester by performing a meticulous 2D transvaginal sonographic examination (Fig. 30).

The diagnostic accuracy and classification of conjoined twins can be improved with the use of color Doppler sonography, MRI and 3D.

Although 2D is adequate to establish a primary diagnosis, 3D provides easily understood images that improve communication with patients, enhance their understanding of the abnormalities involved, and allow them to make better informed decisions about subsequent management.

\section{Comments}

Although the prognosis for conjoined twins is extremely poor, meticulous exploration is necessary to determine which organs are shared and to establish an accurate classification.

Table 3 summarizes the classes of conjoined twinning that can occur.
Table 2: Relationship between the aparition of embryonic division, cause of twinning, and placentation

\begin{tabular}{|c|c|c|}
\hline $\begin{array}{l}\text { Days } \\
\text { after } \\
\text { ovulation }\end{array}$ & $\begin{array}{l}\text { Types of } \\
\text { placentation }\end{array}$ & Twinning cause \\
\hline \multicolumn{3}{|c|}{ Classical model } \\
\hline $1-3$ & Bichorial biamniotic & preimplantation split \\
\hline $3-8$ & Monochorial biamniotic & mixed causes \\
\hline $8-12$ & Monochorial monoamniotic & embryonal disc split \\
\hline $13-15$ & Conjoined & incomplete disc split \\
\hline \multicolumn{3}{|c|}{ Hatching model } \\
\hline 6 & Bichorial biamniotic & $\begin{array}{l}\text { Throphoblastic split in gap } \\
\text { Hatching }\end{array}$ \\
\hline$>6$ & Bichorial monoamniotic & Mixed causes \\
\hline$<6$ & Monochorial monoamniotic & $\begin{array}{l}\text { Split cellular masses and } \\
\text { conjoined internal but not } \\
\text { trophoblast }\end{array}$ \\
\hline
\end{tabular}

Table 3: Classification of conjoined twinning that can occur

\begin{tabular}{|c|c|}
\hline Classes & Place of union \\
\hline Theoracopagus; & Thoracic region (Figs 2 to 4 ) \\
\hline Xiphopagus; & Xiphoid process of sternum \\
\hline Omphalopagus; & Umbilical region (Figs 5 and 6) \\
\hline Rechiopagus; & $\begin{array}{l}\text { Fusion of upper spinal column back- } \\
\text { to-back }\end{array}$ \\
\hline Pygopagus; & Scrum; back-to-back most common \\
\hline Pygodiaymus; & $\begin{array}{l}\text { Cephalothoracic region; duplicate } \\
\text { pelves and lower extremities }\end{array}$ \\
\hline Pygomelus; & $\begin{array}{l}\text { Sacral or coccygeal region; additional } \\
\text { limb or limbs at or near buttock }\end{array}$ \\
\hline Ischiopagus; & Pelvis, ischial region, end-to-end \\
\hline Craniopagus; & Head \\
\hline Iniopagus & \\
\hline $\begin{array}{l}\text { (craniopagus occipitalis) } \\
\text { Epicomus }\end{array}$ & Head, at parasitic occipital region \\
\hline (craniopagus parasiticus); & $\begin{array}{l}\text { Smaller, parasitic twin joined to larger } \\
\text { auto site at occiput }\end{array}$ \\
\hline Monecephalus; & Single head with two bodies \\
\hline Diprosopus; & Single head any body with two face \\
\hline Dicephalus; & $\begin{array}{l}\text { Symmetric body with two head } \\
\text { (Fig. 7) }\end{array}$ \\
\hline Dipygus parasiticus; & $\begin{array}{l}\text { Head and thorax completely merged; } \\
\text { pelyis and lower extremities } \\
\text { duplicated (Figs } 8 \text { and 9) }\end{array}$ \\
\hline Syncephalus; & Face \\
\hline
\end{tabular}

The most common unions occur at the trunk (thoracopagus, xiphopagus, and omphalopagus, but other forms have been observed.

Accurate classification allows physicians to communicate more effectively with their patients and to discuss with them the prognosis and options with greater objectivity. 
During the second and third trimesters of pregnancy, it is difficult to clearly define the separation of fetal structures and organs (head, thorax, etc.) sonographically in cases of conjoined twins. In such cases, it is helpful to identify shared structures by provoking fetal movement with the transducer; this maneuver is easier during the first half of gestation.
The use of transvaginal 2D, color Doppler, and 3D sonography allows the diagnosis and classification of these devastating malformations during the first trimester of gestation. Color Doppler sonography is especially helpful during the first trimester for exploration of shared vessels and vascular organs (Figs 31 to 35).
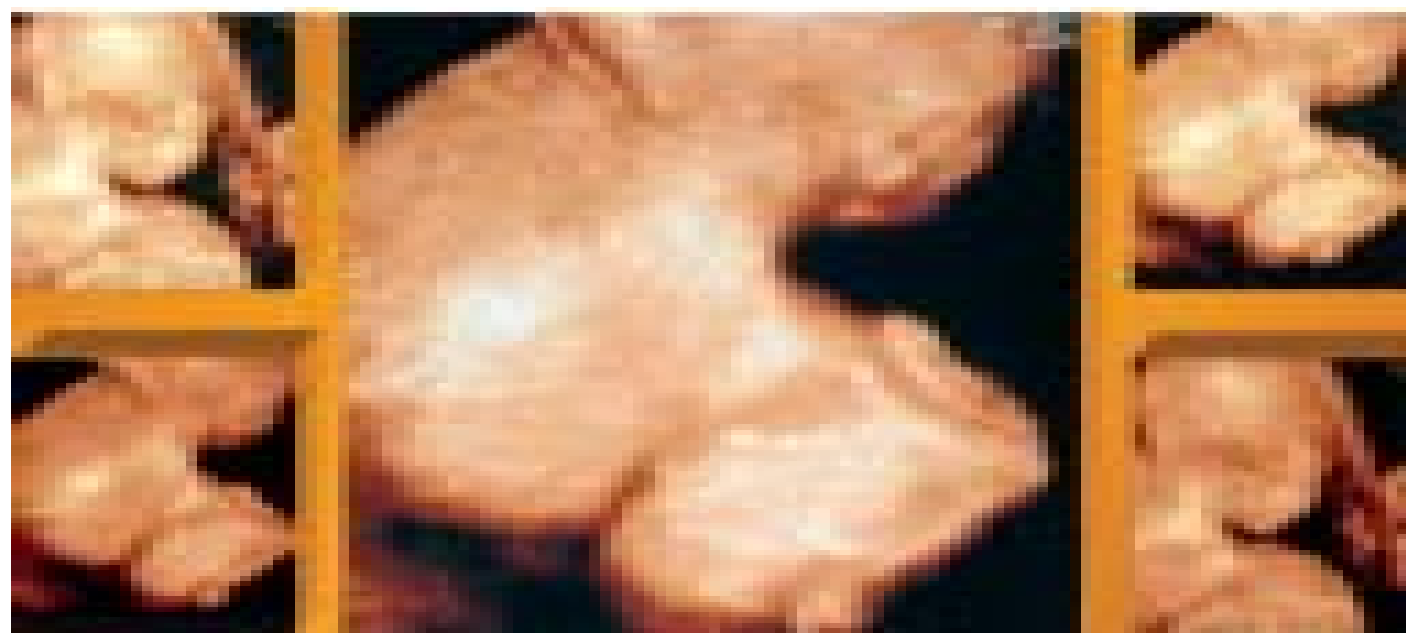

Fig. 31: Dicephalus conjoined twins. This anomaly shows two separated heads, one or beginning of two rachis, one thorax and pelvis and four extremities

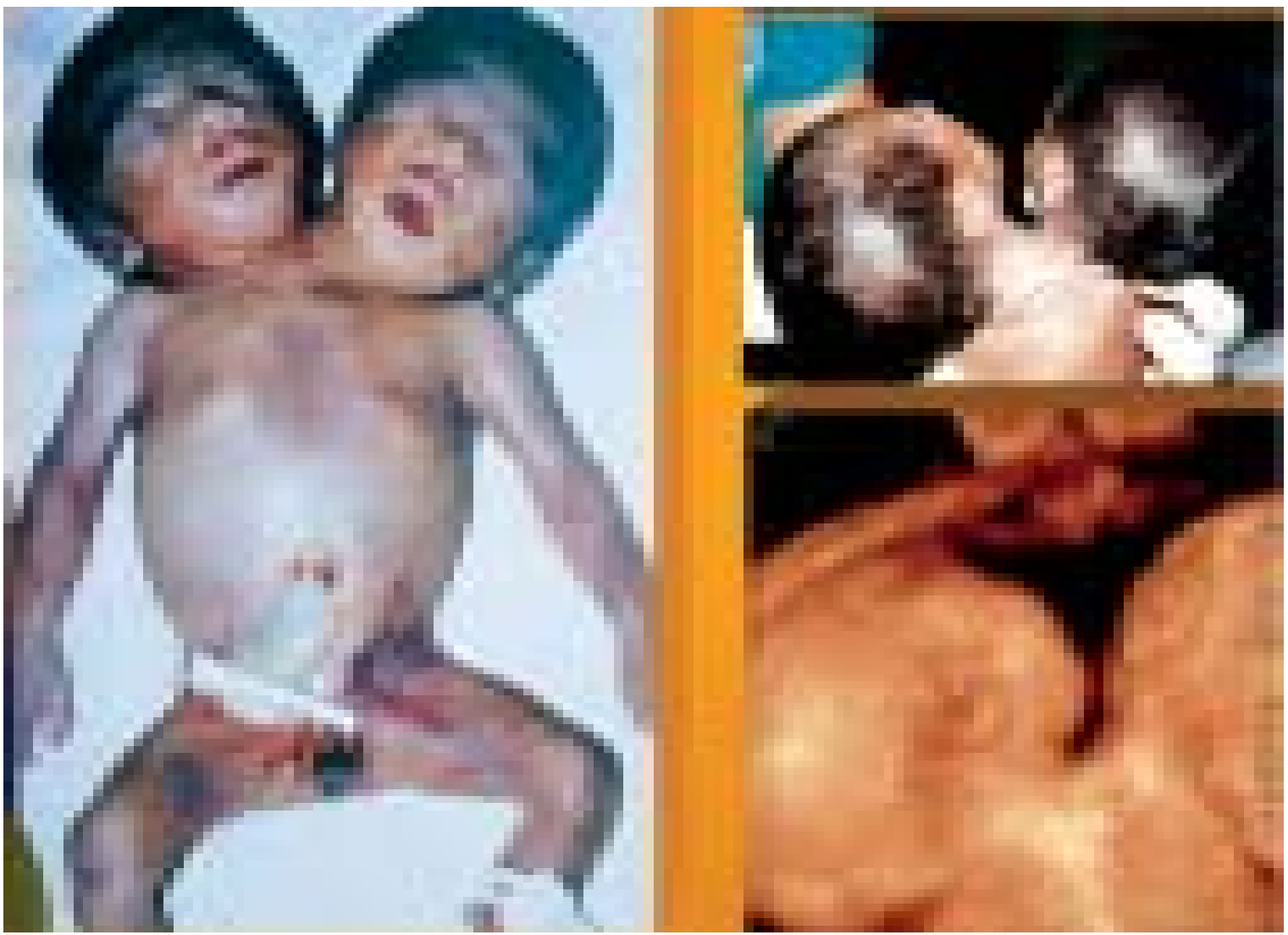

Fig. 32: Dicephalus conjoined twins. Same case of Figure 31 


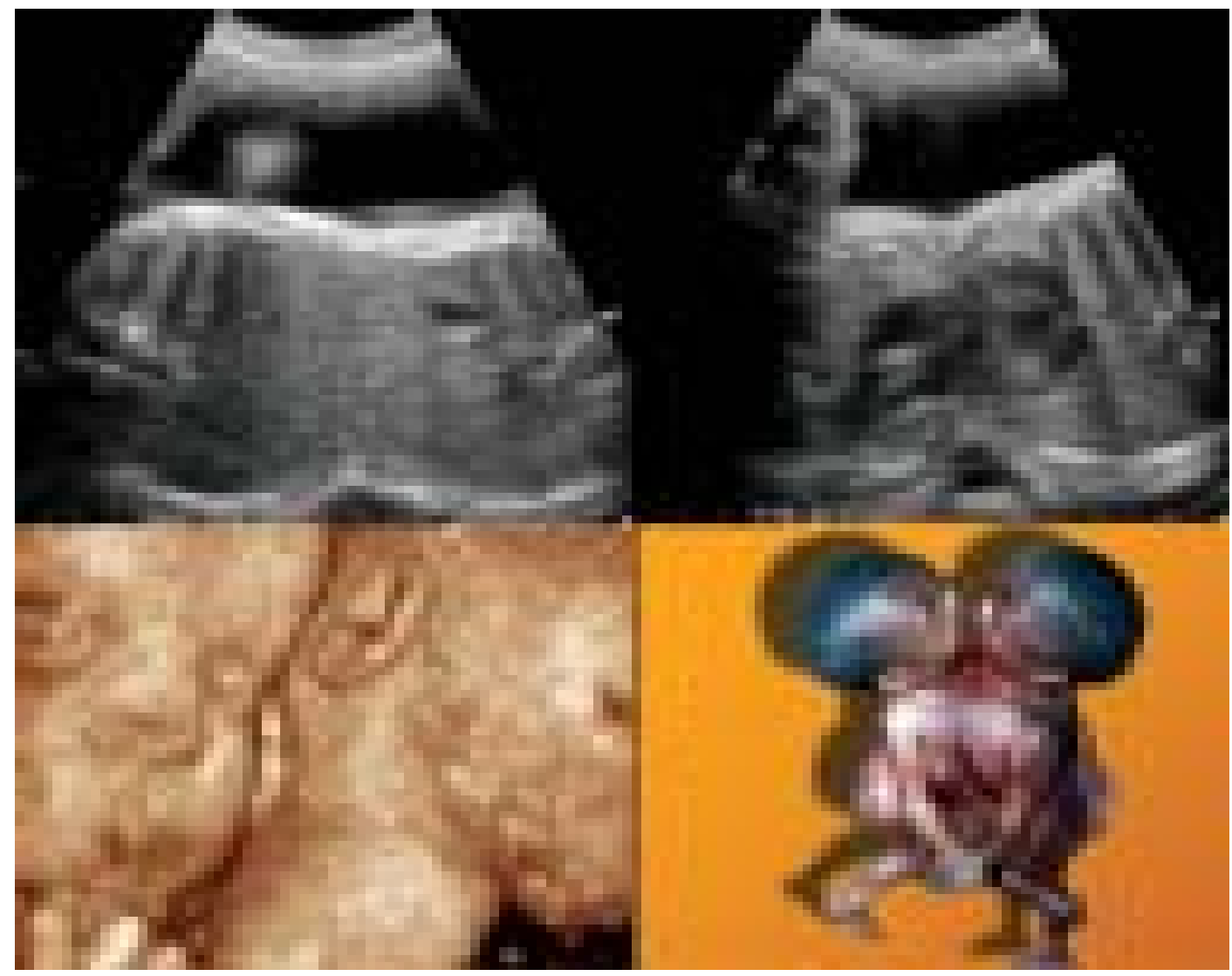

Fig. 33: Thoracopagus: Top, 2D pictures showing the linkage,

two thorax and one heart. Bottom, 3D pictures with both fetuses facing the heads

Two-dimensional ultrasound seems to allow a better assessment of internal anatomy or shared organs than 3D does, but 3D clearly provides images that are much easier for patients to understand than those from 2D.

If the gestation is multifetal, chorionicity and amnionicity are simpler to establish in the first trimester than they are later.

When conjoined twins or other fetal anomalies are identified, 3D sonography is likely to provide images that are easier for the physician and parents to understand than are those from 2D, therefore allowing them to make informed decisions on the basis of more comprehensible information.

\section{Fetus Acardius}

Fetus acardius is an extremely rare complication of monozygotic, multifetal gestation that is thought to result from what is known as the twin reversed arterial perfusion sequence (TRAP).

These very malformed fetuses may have rudimentary heart tissue (pseudoacardius) or may completely lack a heart (holoacardius) (Figs 36 and 37).

This anomaly is always present with other severe fetal malformations. It occurs in 0.3 percent of monozygotic twin gestations, which amounts to a frequency of about one per 35,000 deliveries. Although most cases occur among monozygotic twins, there are reports of acardiac fetuses in triplet and even quintuplet gestations.

Fetus acardius is a consequence of vascular anastomoses in the placenta that result in fetofetal transfusion. Until recently it was thought that the twin with a heart perfused the acardiac twin through at least two anastomoses, one artery-to-artery and one vein-to-vein, and that the circulation of the acardius twin was therefore reversed. There is evidence, however, that vascular anomalies in these cases may be more complex.

Twin-to-twin transfusion may disrupt organogenesis in the recipient in such a way that development of certain "nonessential" organs such as heart brain and arms may not occur. The donor twin may have cardiac hypertrophy cardiac failure intrauterine growth restriction or intrauterine death.

Diagnosis is now possible during the first trimester of pregnancy by detecting inversion of vascular flow in the recipient acardiac fetus with transvaginal Doppler ultrasonography (Fig. 36).

The presence of holoacardius or pseudoacardius in one of the twins may be associated with obstetric complications such 


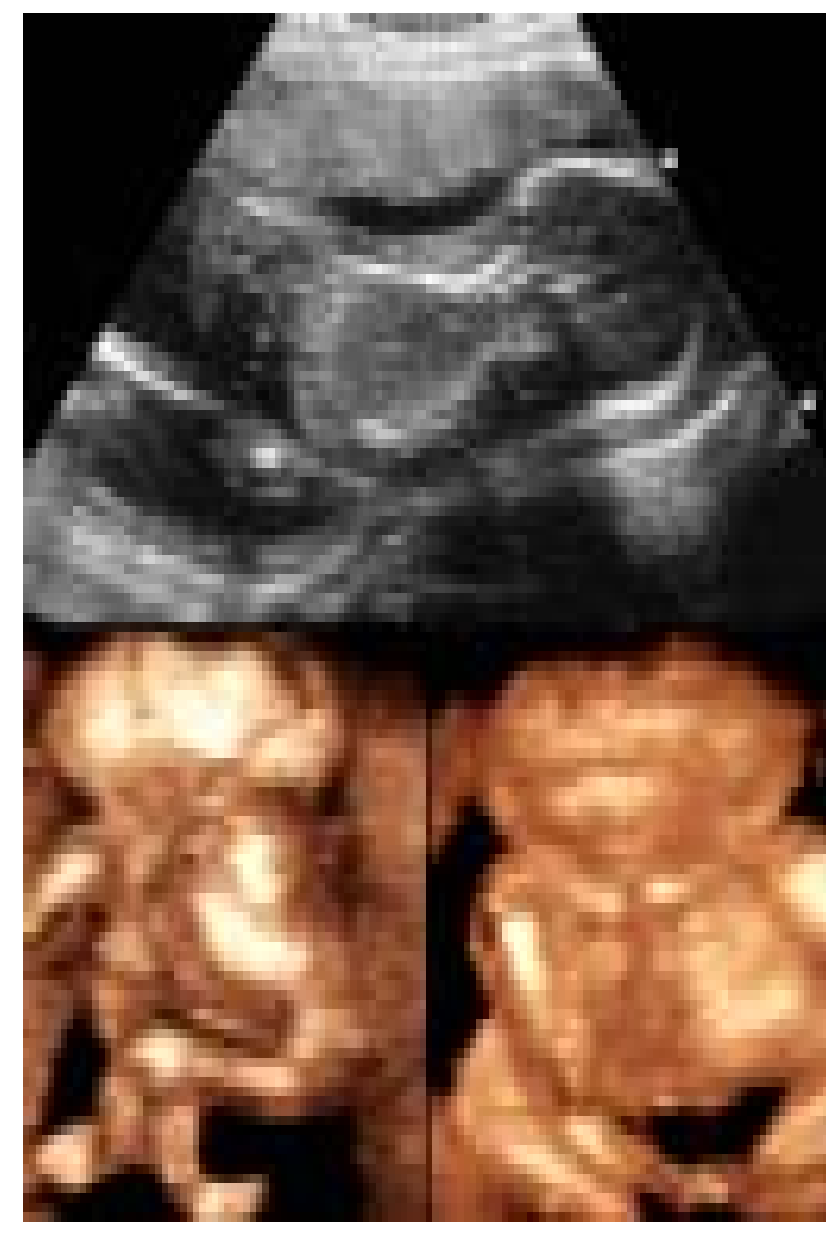

Fig. 34: Dipygus parasiticus

as oligohydramnios polyhydramnios premature rupture of membranes, prematurity, uterine rupture, and hemorrhage.

Early diagnosis of fetus acardius may allow measures to be taken that may help reduce the risk of some of these complications, or even prevent them.

\section{Comments}

Although multifetal gestations are relatively infrequent, they account for a disproportionately large percentage of adverse fetal and maternal outcomes.

Descriptions of acardiac fetuses date back to the 16th century. However, the pathophysiological mechanisms responsible for this anomaly are still not yet clearly understood

\section{Classification}

Existing organic defects have been used to classify acardiac fetuses. The following types have been suggested:

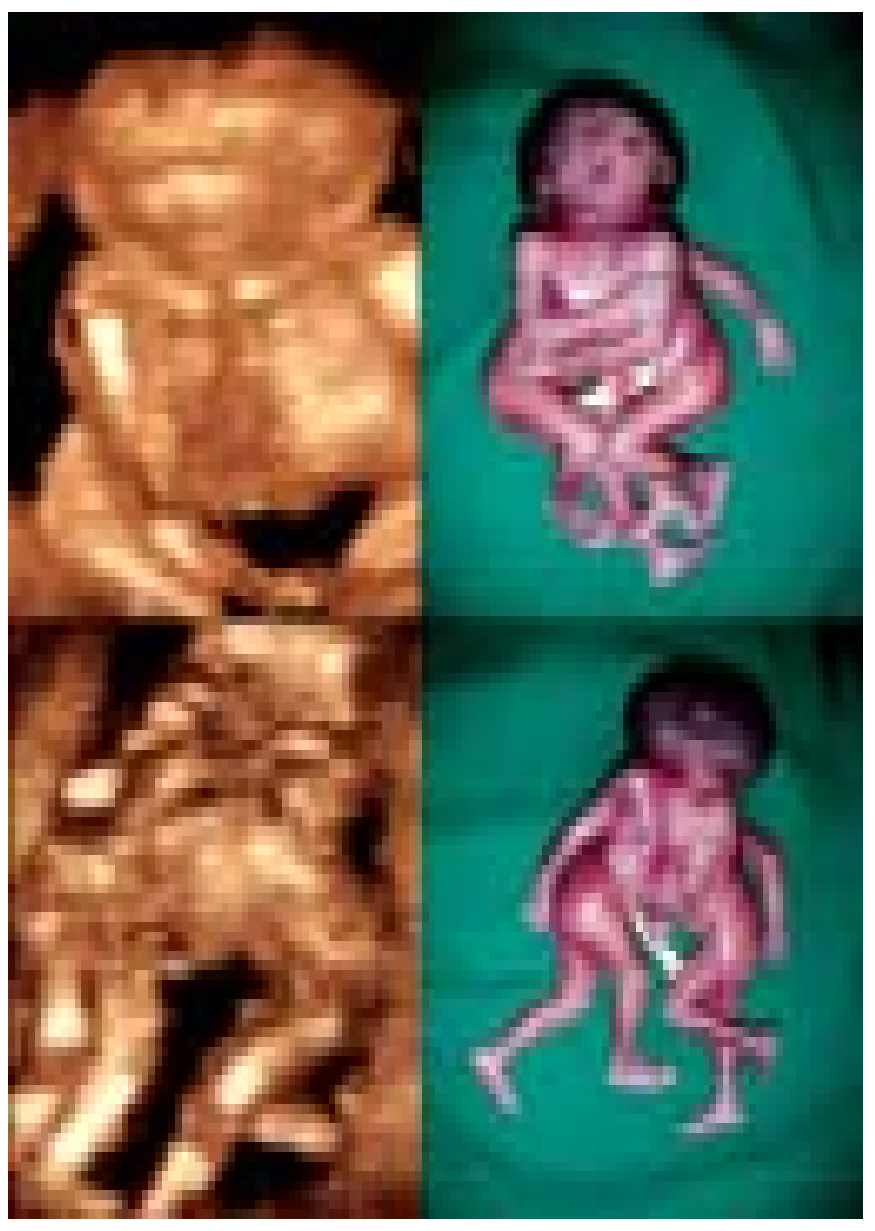

Fig. 35: Dipygus parasiticus. 3D pictures and the newborn

Acardius amorphus: This type of acardiac fetus is the least differentiated form. On histological analysis, only bones, cartilage, muscles, fat, blood vessels, and stroma can be identified. It is the most striking variant. If rudimentary nerve tissue is present, then this form is called myelencephalic acardius. It is likely that some of the teratomas in neonates are remnants of acardius amorphus types of malformation.

Acardius acormus: This type of acardiac fetus lacks a thorax. The umbilical cord inserts in the head. Because rudiments of thoracic structures are almost always found on histological examination, it is debatable whether this variation is real or justified.

Acardius acephalus: This type of acardiac fetus lacks a head, a thorax, and upper extremities. There may be additional malformations in some of the remaining organs. It is the most common type described. Three of the cases in this report are of this type. 


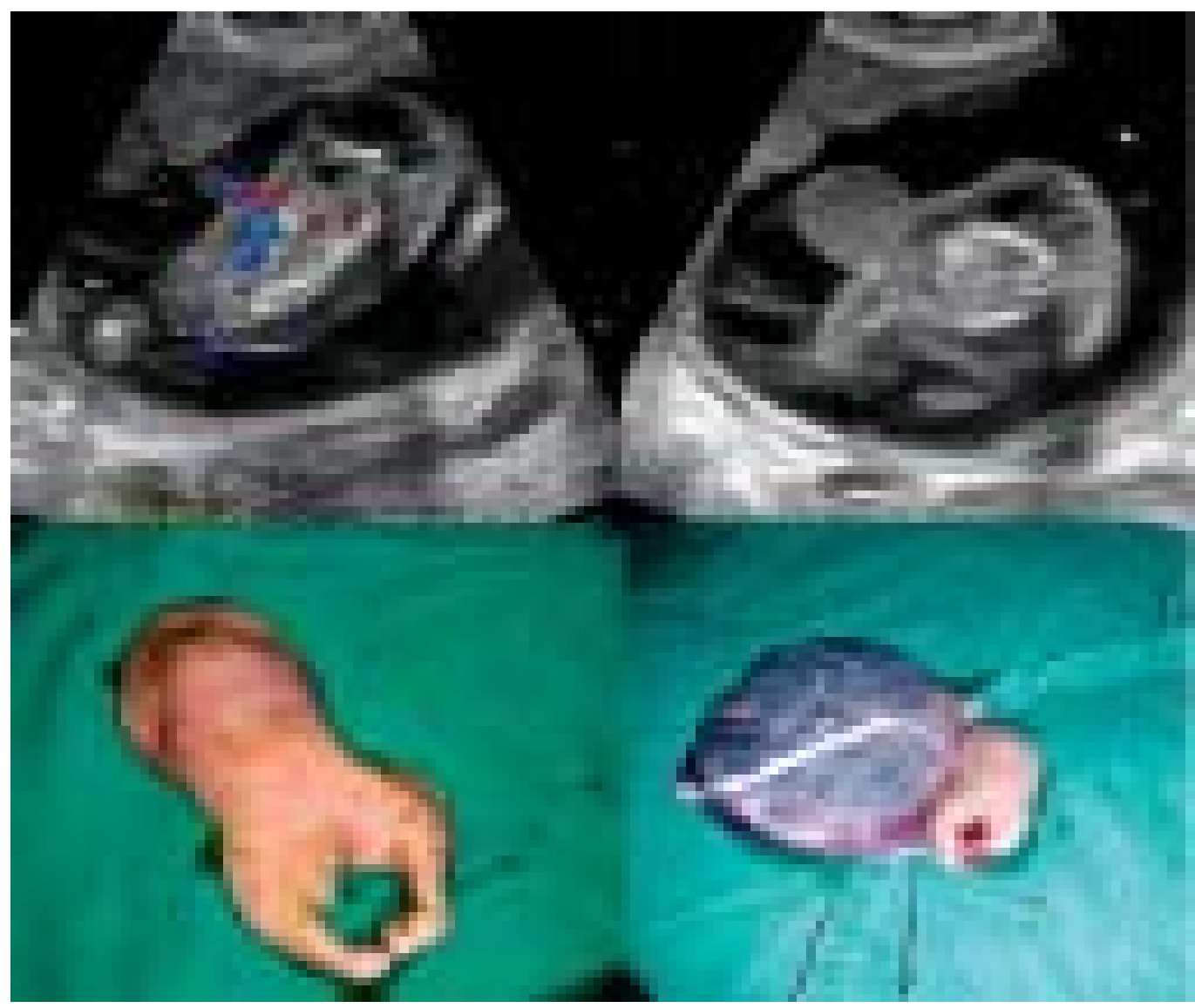

Fig. 36: Acardiac fetus: Observe the absence of a head, well-developed thorax and upper extremities. The lower extremities are abnormal. 3D images are showed in Figure 37

Acardius anceps: This is the purest form of acardiac fetus. These fetuses have a head, a thorax, and abdominal organs, but lack even a rudimentary heart. It is likely that many of the other types start off as acardius anceps and evolve into one of the other forms because of poor oxygen supply.

\section{Ultrasound Diagnoses}

In the 1980s, transabdominal 2D became the method of choice for diagnosing acardius in fetuses. Up to 1990, the number of acardiac fetuses described in the medical literature did not exceed 425 cases. However, because some of these fetuses may be reabsorbed, as occurred with our cases, it is likely that the incidence of this anomaly is greater than suggested by the literature.

With the use of transvaginal Doppler sonography in the 1990s, it became possible to diagnose acardiac fetuses at an earlier gestational age and with greater accuracy.

We may now be able to improve the probability of an uneventful outcome for the normal twin with diagnostic ultrasonographic improvements, including 3D, along with the ability to manage multifetal pregnancies complicated by an acardiac fetus with endoscopy-assisted laser, thermocoagulation, and bipolar coagulation.

At present, early diagnosis by transvaginal 2D depends on observation of the following signs:

1. Monozygotic twin gestation (absence of the lambda sign).

2. Biometric discordance between the twins.

3. Diffuse subcutaneous oedema or morphologic anomalies of one or both of the twins.

4. Absence of cardiac activity (although hemicardius or pseudoacardius may be present).

Biometric discordance, a constant ultrasonographic sign of acardiac fetuses, can be detected as early as the ninth gestational week. Diffuse edema, structural anomalies (predominantly of the cephalic pole), and detection of reversed umbilical cord flow establish the diagnosis. The presence of cardiac activity does not exclude the diagnosis in these cases,

Evidence of cardiac activity may be seen early on if there is hemicardius or pseudoacardius. However, cardiac activity is likely to disappear as the pregnancy progresses, as occurred with one of our cases. This finding supports the vascular theory as the cause of acardiac fetuses. 

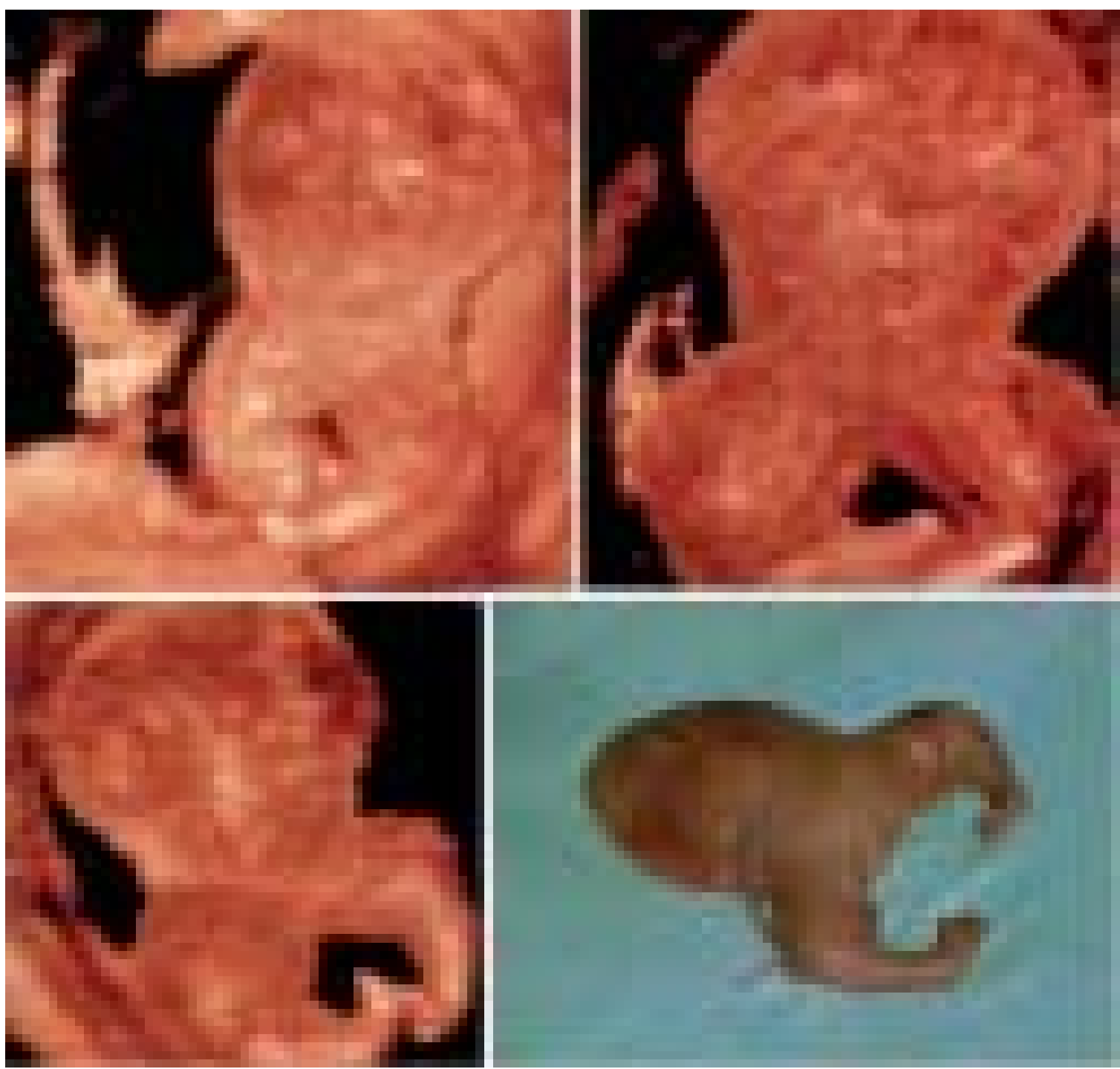

Fig. 37: 3D surface-rendered view of the fetus of Figure 36. Top left and right, 3D sagittal view of the acardiac fetus. Bottom, 3D frontal views. Observe the absence of a head, thorax, and upper extremities, both legs are severely malformed. Bottom right, fetus with acardius acephalus shortly after birth. Compare with the 2D and 3D frontal views of the fetus in Figures 36 and 37

Lack of cardiac activity may be misdiagnosed as evidence of fetal death. The proper diagnosis may be arrived at when serial ultrasonographic images show the progressive growth of the acardiac twin.

Shih reported recently on a Doppler velocimetry study of five acardiac fetuses observed with 3D. Several fetuses were found to have autonomous cardiac activity even when umbilical cord velocimetry patterns were completely different.

They described three velocimetry wave patterns depending on the type of vessels involved in umbilical cord and placental anastomoses:
1. Collision-summation pattern: In this pattern, there is always a primitive, contractile heart and artery-artery anastomosis. The characteristics of this type of wave pattern are as follows:

a. Flow is bidirectional, pumped with two independentpulsation rates and in opposite directions.

b. Cyclic alterations of blood flow occur in consecutive heartbeats.

c. When the peak of the flow toward the acardiac fetus reaches the maximum, the flow away from the acardiac fetus also reaches the maximum. 
d. The waveform of the blood flowing toward the acardiac twin has a variable width, occasionally with two peaks, resembling the summation of two opposite flows at different rates.

2. Artery-vein twin pulse: The inward blood flow streams upward to the trunk rather than downward to the lower limbs, as seen in artery-to-artery anastomases. To our knowledge, this type of flow has been described only once and contradicts the assumption that twin reversed arterial perfusion is the only cause of the variety of disruptive sequences seen in acardiac fetuses.

3. Artery-artery pump-in pattern: Reversed pulsating flow toward the acardiac twin occurs without cyclic alterations. The pump-in index is similar to that of the twin without abnormalities. In these cases, no rudimentary cardiac structures or pseudo-structures are observed in the acardiac twin.

In all cases, the velocimetry wave pattern of the donor fetus was normal and independent of whether fetal death took place subsequently. The recipient fetus is transfused by reversed perfusion with oxygen-depleted blood frequently ( $50 \%$ of cases) via a single-artery umbilical cord.

We think that the twin reversed arterial perfusion sequence becomes established very early in embryogenesis, while there is still reduced dependence on vascular oxygen supply, because maternal circulation in the intervillous spaces is not yet fully developed.

Although a full explanation for the extent and degree of organ regression remains elusive, it seems likely that incomplete morphogenesis and regression of certain fetal structures, especially of the circulatory system, result from early establishment of reversed blood flow.

Theoretically, agenesis of the lower extremities should be more severe in cases of arteriovenous anastomoses, because in these cases the direction of blood perfusion is dorso-cranial, presumably following the course of the primitive cardinal vein, rather than toward the lower extremities, as seen in cases of artery-artery anastomases. The lack of correlation between theory and observation contradicts the assumption that reversed flow in artery-artery anastomosis is the only cause of acardiac fetuses.

Although much of the work with newer imaging techniques is still in the initial stages, we anticipate the eventual development of prognostic criteria for intervention on behalf of donor fetuses by the use of hemodynamic and biometric ultrasonographic criteria such as the degree of polyhydramnions, fetal weight, the impedance of umbilical arteries, and the left ventricle ejection fraction of the donor fetus.

Recent reports suggested that an embryopathy is responsible for the initial lesion, probably before day 26 after conception. Such a lesion would cause an alteration in the primitive vascular development, as is the case with other malformations such as anencephaly and omphalocele. It is of interest that of the seven fetuses we observed in this series, only one was normal. Undoubtedly; vascular anomalies play an important role in the pathogenesis of fetal acardius. However, it is likely that fetal acardius results from a combination of factors.

\section{BIBLIOGRAPHY}

1. Biggio JR Jr, Wenstrom KD, Owen J. Fetal open spina bifida: A natural history of disease progression in utero. Prenat Diagn 2004;24:287-9.

2. Biggio JR, Owen J, Wenstrom KD, et al. Can prenatal ultrasound findings predict ambulatory status in fetuses with open spina bifida? Am J Obstet Gynecol 2001;185:1016-20.

3. Blaas HG, Eik-Nes SH, Isaksen CV. The detection of spina bifida before 10 gestationa 1 weeks using twoand threedimensional ultrasound. Ultrasound Obstet Gynecol 2000;16:25-9.

4. Bonilla-Musoles F, Machado L, Osborne N, Bonilla Jr. F, Raga F, Machado F. Neural tube defects. In Bon Illa-Musoles F, Machado L (Eds): 3D-4D Ultrasound in Obstetrics. Panamericana Ed. Madrid. 2004;269-76.

5. Bonilla-Musoles F, Machado L, Osborne N. Malformations of the medullary canal. In Bonilla-Musoles F, Machado L, Osborne N. Three-Dimensional Ultrasound for the New Millenium.Text and Atlas. Aloka Pblh Madrid 2000;193-204.

6. Bonilla-Musoles F, Machado LE, Osborne NG, et al. Two and three-dimensional ultrasound in malformations of the medullary canal: report of 4 cases. Prenat Diagn 2001;21:622-6.

7. Bonilla-Musoles F, Raga F, Villalobos A, Osborne N, Blanes J. First-trimester neck abnormalities: three-dimensional evaluation. J Ultrasound Med 1998;17:419-26.

8. Budorick NE, Pretorius DH, Grafe MR, et al. Ossification of the fetal spine. Radiology 1991;181:561-5.

9. Dyson RL, Pretorius DH, Budorick NE, et al. Three-dimensional ultrasound in the evaluation of fetal anomalies. Ultrasound Obstet Gyneco1 2000;16:321-8.

10. Garjian KV, Pretorius D, Budorick N, Cantrell C, Johson D, Nelson T, Fetal skeletal dysplasia: Three-dimensional US-Initial experience. Radiology 2000;214:717-23.

11. Gray DL, Crane JP, Rudloff MA. Prenatal diagnosis of neural tube defects: origin of mid trimester vertebral ossification centers as determined by sonographic water-bath studies. J Ultrasound Med 1988;7:421-7.

12. Johnson DD, Pretorius DH, Riccabona M, et al. Threedimensional ultrasound of the fetal spine. Obstet Gynecol 1997;89:434-8.

13. Kollias SS, Goldstein RE, Cogen PH, Fiily RA. Prenatally detected myelomeningoceles: Sonographic accuracy in estimation of the spinal 1evel. Radiology 1992;185:109-12.

14. Lee W, Chaiworapongsa T, Romero R, et al. A diagnostic approach for the evaluation of spina bifida by threedimensional ultrasonography. J Ultrasound Med 2002;21:619-26.

15. Ludomirski A, Khandelwal M, Uerpairojkit B, Reece EA, Chan L. Three-dimensional ultrasound evaluation of fetal facial and spinal anatomy. Am J Obstet Gynecol 1996;174 (supl)4: 318. 
16. Menkes JH, Sarnat HE. Neuroembryology, genetic programming, and malformations. En: Child Neurology. 6 Ed. Philadelphia, FA: Lippincott Williams \& Wilkins; 2000;316-35.

17. Müller GM, Weiner CP, Yankowitz J. Three-dimensional ultrasound in the evaluation of fetal head and spine anomalies. Obstet Gynecol 1996;88:372-8.

18. Nelson TR, Pretorius DH. Visualization of the fetal thoracic skeleton with three-dimensional sonography:a preliminary report. Am J Roentgenol 1995;164:1485-8.

19. Pooh Riz, Maeda K, Pooh KH. An atlas of fetal central nervous system disease. Diagnosis and management. London: Parthenon/ CRC Press, 2003.

20. Pooh Riz, Pooh Izh. Fetal neuroimaging with new technology. Ultrasound Review Obstet Gynecol 2002;2:178-81.

21. Pooh RK, Pooh KH. Fetal vertebral structure detected by threedimensional ultrasound. Ultrasound Rev Obstet Gynecol 2005;5:29-33.
22. Riccabona M, Johnson D, Pretorius DH, et al. Three dimensional ultrasound: display moda1ities in the fetal spine and thorax. Eur J Radio1 1996;22:141-5.

23. Schild RL. Fetal lumbar spine volumetry by three-dimensional ultrasound. Ultrasound Obstet Gynecol 1999;13:335-9.

24. Schild RL, Wallny T, Fimmers R, Hansmman M. The size of the fetal thoracolumbar spine: a three-dimensional ultrasound study. Ultrasound Obstet Gynecol 2000;16:468-72.

25. Steiner H, Staudach A, Zajc M, Wienerroither H. Verbesserte Diagnostik am fetalen Skelett mittels 3D-Sonographie. Ultraschall Klin Prax 1994;8:154.

26. Wallny TA. The fetal spinal canala three dimensional study. Ultrasound Med Biol 1999;25:1329-38. 